\title{
Metabolic syndrome among children and adolescents in low and middle income countries: a systematic review and meta-analysis
}

\author{
Zebenay Workneh Bitew ${ }^{1^{*}}$ (D) Ayinalem Alemu², Ermias Getaneh Ayele ${ }^{1}$, Zelalem Tenaw ${ }^{3}$, Anmut Alebel ${ }^{4,5}$ \\ and Teshager Worku ${ }^{6}$
}

\begin{abstract}
Background: Metabolic syndrome (MetS) is a clustering of cardiovascular risk factors, which is rising in the low and middle income countries (LMICs). There are various studies with inconsistent findings that are inconclusive for policy makers and program planners. Thus, this systematic review and meta-analysis aimed at estimating the pooled prevalence of MetS and its components in LMICs.
\end{abstract}

Methods: Electronic searches were conducted in international databases including PubMed, Web of Science, EMBASE (Elsevier), Scopus, CINAHL (EBSCOhost), Science direct (Elsevier), Food Science and Technology Abstracts (FSTA), Global Health and Medline, and other sources (World Cat, Google Scholar, and Google). The pooled estimates were computed in the random effect model. The pooled prevalence was computed using the three diagnostic methods (IDF, ATP III and de Ferranti). Publication bias was verified using funnel plot and Egger's regression test. Subgroup and sensitivity analysis were performed to identify the possible sources of heterogeneity among the included studies.

Result: In this study, 142,142 children and adolescents from 76 eligible articles were included to compute the pooled prevalence of MetS and its components in LMCls. MeTs among overweight and obese population was computed from 20 articles with the pooled prevalence of $24.09 \%, 36.5 \%$, and $56.32 \%$ in IDF, ATP III and de Ferranti criteria, respectively. Similarly, a total of 56 articles were eligible to compute the pooled prevalence of MetS in the general population of children and adolescents. Hence, Mets was found in 3.98\% (IDF), $6.71 \%$ (ATP III) and $8.91 \%$ (de Ferranti) of study subjects. Regarding the components of MetS, abdominal obesity was the major component in overweight and obese population and low HDL-C was the most common component in the general population. This study also revealed that males were highly affected by MetS than females.

Conclusion: This study illustrates that MetS among children and adolescents is an emerging public health challenge in LMICs, where the prevalence of obesity is on the move. Preventive strategies such as community and school based intervention need to be designed. Promoting physical activities and healthy eating behaviors could avert this problem.

Keywords: Metabolic syndrome, MetS, Components of metabolic syndrome, Low and middle income countries, Lmics

${ }^{*}$ Correspondence: zedo2015@gmail.com

1 St. Paul's Hospital Millennium Medical College, Addis Ababa, Ethiopia

Full list of author information is available at the end of the article

\section{Background}

Metabolic syndrome (MetS) is a constellation of interconnected risk factors of metabolic origin leading to atherosclerotic cardiovascular diseases [1]. The common risk factors include elevated triglycerides, altered 
glucose metabolism, reduced high density lipoprotein cholesterol (HDL-C), and elevated blood pressure and adiposity [2]. It usually resulted from dysregulated cellular metabolism, leading to insulin resistance [3]. MetS is also associated with a multitude of disorders such as diabetic mellitus, increased uric acid level, hepatic steatosis, polycystic ovarian syndrome, and obstructive sleep apnea [4-8].

There are various diagnostic methods for MetS in children and adolescents. According to the International Diabetes Federation (IDF), MetS is diagnosed if children aged between $10-16$ years have central adiposity ( $\geq 90$ th) and two of the followings: triglycerides (TG) $\geq 150 \mathrm{mg} /$ $\mathrm{dl}, \quad \mathrm{HDL}-\mathrm{C}<40 \mathrm{mg} / \mathrm{dl}$, systolic blood pressure $(\mathrm{BP}) \geq 130 \mathrm{mmHg}$ or diastolic $\mathrm{BP} \geq 85 \mathrm{mmHg}$, fasting plasma glucose (FG) $\geq 100 \mathrm{mg} / \mathrm{dl}$ or previously diagnosed type 2 diabetes [9]. Based on the WHO criteria, MetS is diagnosed when three or more of the following features are found: body mass index (BMI): $>95$ th percentile, hyperinsulinemia or impaired fasting glucose or impaired glucose tolerance, $\mathrm{BP}>95$ th percentile, TG $>105 / 136 \mathrm{mg} /$ $\mathrm{dL}(1.2 / 1.5 \mathrm{mmol} / \mathrm{L})$ for children aged $<10$ and $>10$ years respectively, HDL-C $<35 \mathrm{mg} / \mathrm{dL}$ ( $0.9 \mathrm{mmol} / \mathrm{L})$ [10]. Adult Treatment Panel III (ATPIII) criteria modified for age defines the presence of MetS when three of the following criteria are met: $\mathrm{TG} \geq 110 \mathrm{mg} / \mathrm{dl}, \mathrm{HDL}-\mathrm{C} \leq 40 \mathrm{mg} /$ $\mathrm{dl}$, systolic $\mathrm{BP}$ or diastolic $\mathrm{BP} \geq 90$ th, $\mathrm{WC} \geq 90$ th percentile for age and gender. percentile for age and gender and FG $\geq 110 \mathrm{mg} / \mathrm{dl}$ [11]. In accordance with de Ferranti et al. MetS is clustering of at least three of the following criteria: $\mathrm{FG} \geq 110 \mathrm{mg} / \mathrm{dl}$, HDL-C $\leq 50 \mathrm{mg} / \mathrm{dl}$ (except in boys aged 15 to 19 years in whom the cut point is $45 \mathrm{mg} / \mathrm{dl}$ ), $\mathrm{TG} \geq 100 \mathrm{mg} / \mathrm{dl}$, systolic $\mathrm{BP}>90$ th percentile for gender, age and height, $\mathrm{WC}>75$ th percentile for age and gender [12], whereas Cook et al. depicted that MetS is diagnosed when there or more of the following criteria are met: WC $\geq 90$ th percentile, $F G \geq 110 \mathrm{mg} / \mathrm{dL}(\geq 6.1 \mathrm{mmol} / \mathrm{L})$, $\mathrm{TG} \geq 110 \mathrm{mg} / \mathrm{dL}, \mathrm{HDL}-\mathrm{C} \leq 40 \mathrm{mg} / \mathrm{dL}(1.03 \mathrm{mmol} / \mathrm{L})$ and $\mathrm{BP} \geq 90$ th percentile [13].

The prevalence of MetS in children and adolescents remains unclear [14]. However, a previous review revealed that it ranged from 0.2 to $38.9 \%$, with a median of $3.3 \%$ (range, $0-19.2$ ) in the general population and relatively higher in overweight (11.9\%) and obese (29.2\%) children [14-16]. These reports depicted that MetS in children and adolescents is increasingly becoming a major public health concern [17]. Accordingly, study findings concerning MetS among children and adolescents reported in low and middle-income countries (LMICs), are highly inconsistent and varied across countries. For instance, it is estimated to be as high as $22 \%$ in Iranian children and adolescents with sizable variations among the diagnostic methods [18].
A previous study has outlined that plenty of factors, primarily related to lifestyle [19], are significantly associated with an increased incidence of MetS. Consumption of fructose in the form of soft drinks, juice, and baked goods remarkably upsurge in the past four decades, which contributed to the emergence of obesity, the main predictor of MetS in children and adolescents [20-22]. It has significantly increased since 1980 contributing to $6-39 \%$ of MetS in children and adolescents [23]. Currently, obesity is one from the three global syndemics along with undernutrition and climate change, affecting both children and adults globally [24]. This problem is increasing alarmingly in developing countries due to the recent nutritional and demographic transitions [25].

Evidence-based systematic reviews are essential to inform program planners and policy-makers. However, to the best of our knowledge, systematic reviews in this area are minimal, especially in LMICs. Therefore, the main purpose of this systematic review and meta-analysis was to determine the pooled prevalence of MetS in children and adolescents in LMICs using different diagnostic methods. The findings will be very informative for policy-makers and program planners in designing preventive strategies accordingly. The results will also have a particular implication for developing countries, where the triple burden of malnutrition prevails [26]. Besides, this study will be decisive to design preventive measures for non-communicable diseases (NCDs) in the LMICs, where the trend of NCDs is increasing.

\section{Methods}

\section{Eligibility criteria and information sources}

In this systematic review and meta-analysis, studies conducted in LMICs with an objective of assessing the prevalence of MetS among children and adolescents were included. The studies were assessed using study area, study setups, title, abstract, and full texts prior to inclusion in this study. This study was prepared based on the Preferred Reporting Items for Systematic Reviews and Meta-analysis (PRISMA) guideline [27]. In the present study, published articles, surveys, and unpublished articles that were conducted in English were explored and included accordingly. Besides, the reference lists of included articles were checked for additional studies. Observational studies reporting the prevalence of MetS among children and adolescents conducted both in clinical and community based setups were included. Studies published until July, 2020 were searched.

However, articles with incomplete diagnostic methods and which were not fully accessible were excluded. The corresponding authors of the primary studies were communicated by email before the decision of exclusion was made. Conference proceedings and qualitative studies 
were also excluded. The EndNote X8 reference manager was used to manage retrieved articles.

\section{Search strategy and study selection}

A comprehensive systematic literature search was conducted by three investigators (ZWB, AA, and TW), independently. During the searching process, we consulted a senior librarian working at St. Paul's Hospital Millennium Medical College, Ethiopia A literature search for available articles published in English was performed using the following databases: PubMed, Web of Science, EMBASE (Elsevier), Scopus, CINAHL (EBSCOhost), Science direct (Elsevier), Food Science and Technology Abstracts (FSTA), Global Health and Medline, up to July 2020. The grey literature sources (World Cat, Google Scholar, and Google) were also explored to find out additional articles. Searching was conducted using the following key terms: (a) population (children, adolescent, child, school age); (b) exposure (associated factors, risk factors, determinants, predictors) (c) outcome (metabolic syndrome, MetS, components of metabolic syndrome); (d) study design (cohort studies, cross sectional studies, epidemiology, observational, national health surveys); (e) study setting (school, community based surveys, health institutions) and (f) location (low and middle-income countries, LMICs, developing countries, names of low and middle income countries). The Boolean search operators such as "OR", "AND" were used during the searching process. Key terms were verified for appropriateness prior to actual searching. Example of search string in PubMed (Table 1).

\section{Data extraction process}

Three authors (ZWB, AA, and EGA) extracted data from included articles using a standardized data extraction form. First, the data were stored in Microsoft excel, 2016 by two authors (ZWB, AA, and EGA), independently. Next, the data were cleaned and made ready for the final analysis using the excel spreadsheet. Finally, the data were exported to the STATA software for analysis. The data extraction format included: name of the author (s), publication year, study country, sample sizes, age of the study population, population group, MetS with diagnostic methods, and components of MetS. Discrepancies between the authors were solved through discussion and consensus, and with active involvement of the other author (ZT) (Additional file 1).

\section{Table 1 Search string used for searching articles from Pubmed}

\begin{tabular}{|c|c|}
\hline Population & (Children) OR (school children)) OR ("Child"[Mesh])) OR ("Adolescent"[Mesh]) \\
\hline Outcome & ("Prevalence"[Mesh] AND "epidemiology" [Subheading]) AND ("Metabolic Syndrome"[Mesh]) \\
\hline Study region/country & 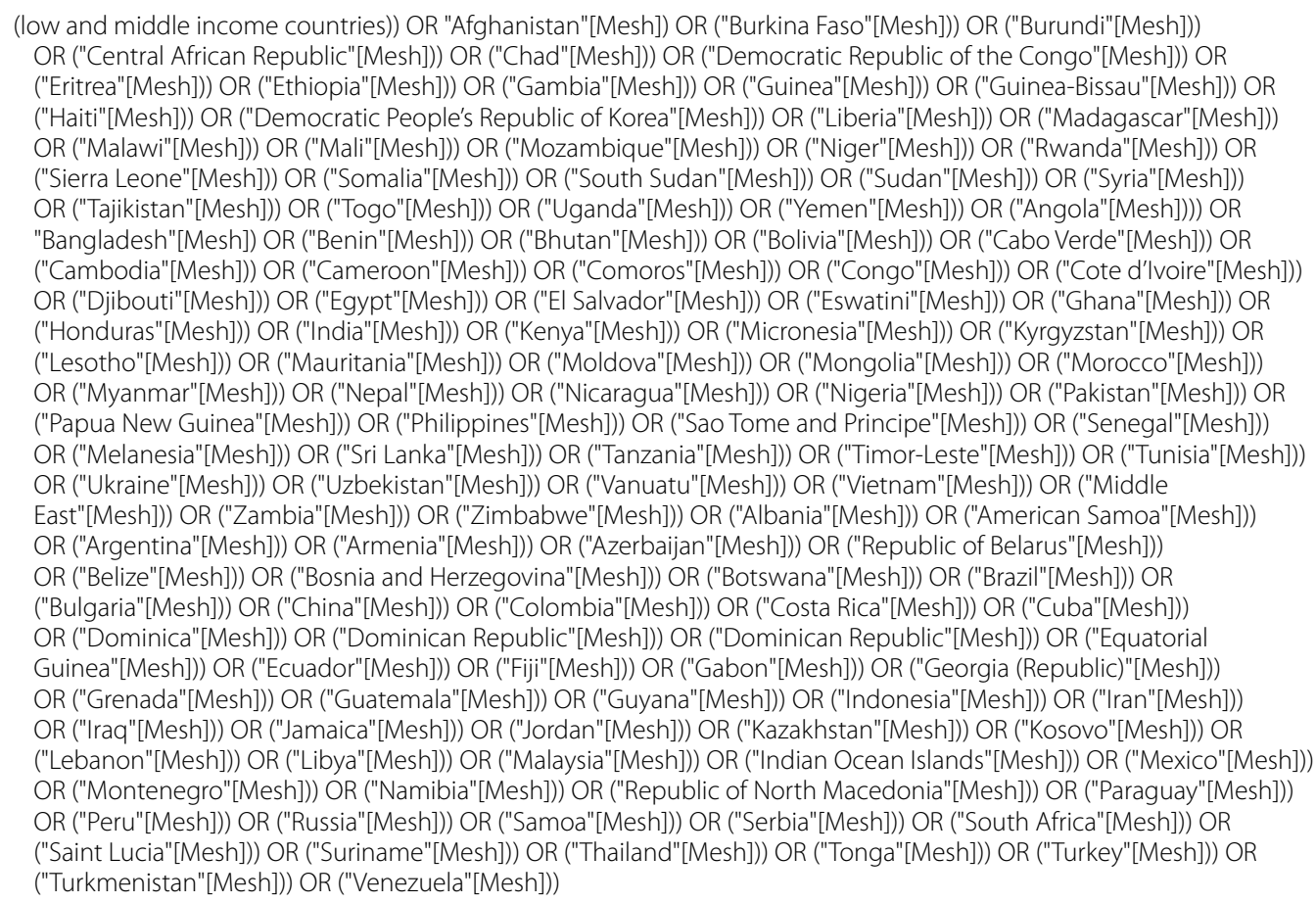 \\
\hline Filters & Filters: Free full text, Observational Study, in the last 10 years, Humans, English, Child: 6-12 years, Adolescent: $13-18$ years \\
\hline
\end{tabular}




\section{Quality assessment of studies}

Two authors (ZWB \& AA) independently assessed the quality of included studies using a Joanna Briggs Institute (JBI) Critical Appraisal Checklist for Observational Studies [28]. The tool has four options (Yes, No, Unknown, and Not Applicable). One is given for yes and zero for other options. The minimum score was zero and the maximum was eight. The scores were summed up and changed to percentages. Studies with quality scores of $>50 \%$ were included in this meta-analysis (Additional file 2). The mean scores of the two reviewers were used for final decision of inclusion of the studies in this systematic review and meta-analysis. During critical appraisal, the author (ZT) participated actively in solving differences between the two authors.

\section{Summary measures}

The primary outcome of this study was the prevalence of MetS among children and adolescents in LMICs using various diagnostic methods. The pooled prevalence of MetS was calculated in the general population and overweight and/or obese children and adolescents separately. The general population includes underweight, normal weight, overweight and obese children and adolescents. The other outcomes were components of metabolic syndromes, the prevalence of MetS based on country, continent, and economic level of countries, where the original studies were done. Based on economic level, LMICs were further divided in to low income economies (LIE), lower middle income economies (LMIE), and upper middle income economies (UMIE) [29]. The pooled prevalence of MetS was also computed among males and females. The prevalence was calculated by dividing the total number of events (MetS) to the total sample size and multiplying it by 100 . The binomial distribution formula was used to compute the standard error for each original study. The "metan" commands were used to compute the pooled estimates using STATA (version 15) software. The pooled estimates were presented with their $95 \%$ CIs. The effect sizes were prevalence of MetS in LMICs and the respective components of MetS.

\section{Statistical methods and analysis}

In the current meta-analysis, STATA Version 15 (STATA Corporation, College Station Texas) software was used for computing the pooled estimates. The pooled estimates were computed using both random and fixed effect models. Due to the presence of high heterogeneity among studies, the pooled estimates were computed using random-effects models and were weighted using the inverse variance method. Subgroup analyses were performed using different parameters. The pooled estimates in the general and overweight and/or obese population were presented separately. For the subgroup analysis, data were extracted based on study continent, study county, the economic level of the study countries, type of diagnosis and gender of study subjects. The appropriateness of each datum was verified before the analyses. The pooled estimates were presented with their 95\% CIs. Likewise, the heterogeneities among the included studies in the pooled estimates were presented with $\mathrm{I}^{2}$ test statistic and P-value. The results of meta-analyses were presented using forest plot, summery tables, and texts.

\section{Publication bias and heterogeneity}

Publication bias was assessed using the funnel plot asymmetry and Egger's regression test at a 5\% significant level [30]. Heterogeneity among included studies was explored using forest plot, $\mathrm{I}^{2}$ test, and the Cochrane Q statistics [31]. The $\mathrm{I}^{2}$ values of $25 \%, 50 \%$, and $75 \%$ were interpreted as low, medium, and high heterogeneity, respectively [32]. In this meta-analysis, significant heterogeneity was considered when the $\mathrm{I}^{2}$ value was $\geq 50 \%$, with $\mathrm{P}$-value $<0.05$. The possible sources of significant heterogeneity were addressed through sub-group and sensitivity analyses.

\section{Results}

\section{Selection of eligible studies}

A total of 4597 articles were obtained in the initial search. After removal of 478 due to duplicates, 4119 were remained and screened for titles and abstracts. Following this, 4018 studies were removed after reading titles and abstracts. The full texts of 101 articles were downloaded and assessed for eligibility criteria. Twenty five studies were excluded due to the following exclusion criteria: different study population, no full test, unclear diagnostic criteria, letter to editor, written in non-English language, and different study design (Additional file 3). Finally, 76 articles [33-108] were included in the final analysis in this meta-analysis (Fig. 1).

\section{Characteristics of the included studies}

All studies included in this study were cross-sectional studies. Regarding study population, 20 studies [35, 47, 50, 55, 57, 58, 63, 69, 71, 72, 77, 79, 84, 87-89, 91, 92, 95, 104] were conducted among overweight and/or obese children and adolescents, and 56 studies [33, 34, 36-46, $48,49,51-54,56,59-62,64-68,70,73-76,78,80-83,85$, $86,90,93,94,96-103,105-108]$ were conducted among the general population of children and adolescents. This review included 142,142 study participants from 76 articles. Of which, 138,236 were the general population, whereas 3906 were overweight and obese population. The sample size of included studies ranged from 51 in Tunisia [58] to 37,504 in Brazil [52]. The age of study population across the included studies ranged between 5 


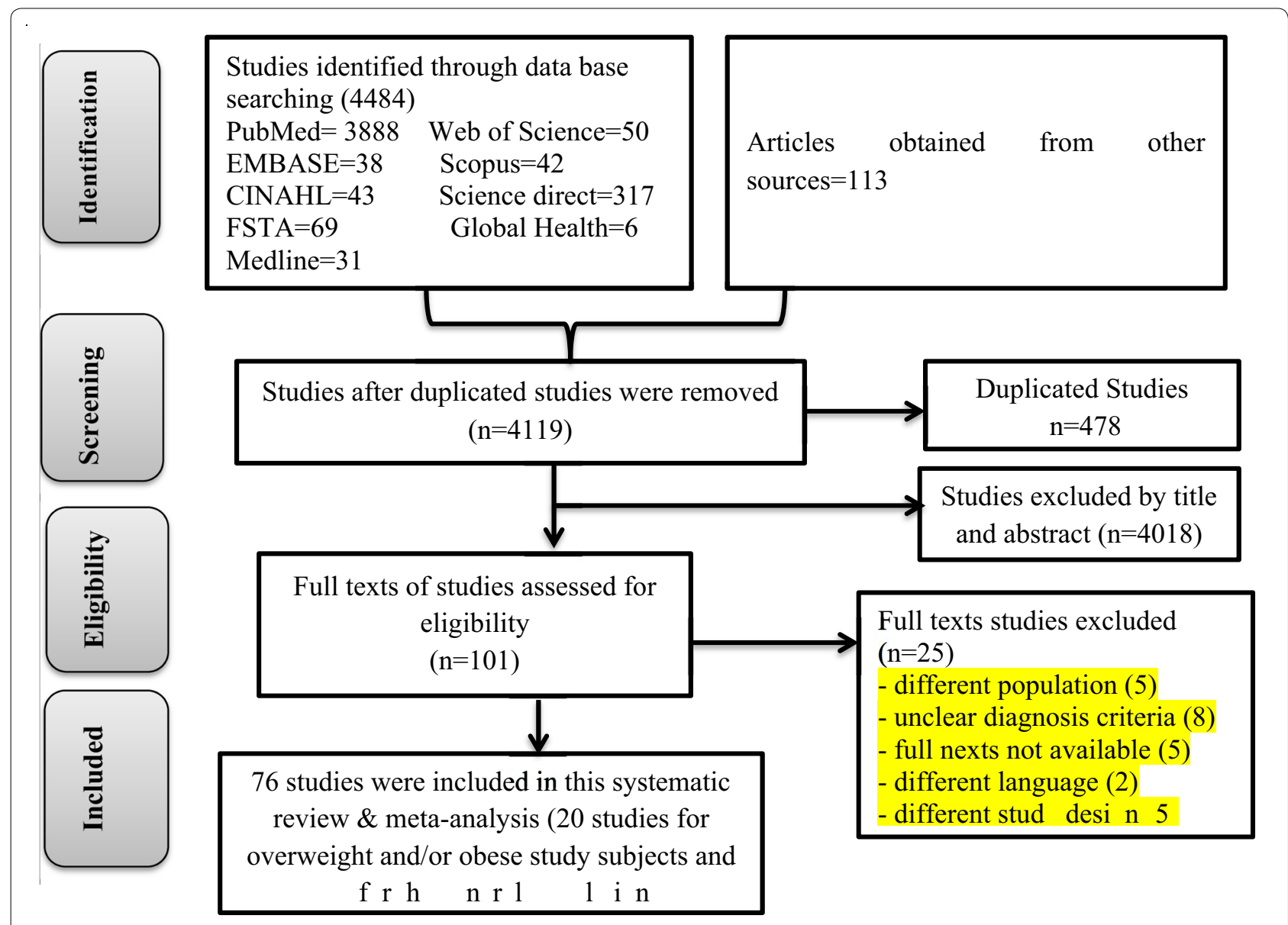

Fig. 1 PRISMA flow chart showing study selection process

to 20 years. Most of the studies were conducted in UMIE Asian countries and very few articles were found from Africa. The quality of articles was also assessed using the JBI checklist, and 56 articles had medium quality. The remaining 20 studies had high quality (Tables 2,3 ).

\section{Prevalence of MetS and components among overweight and obese children and adolescents}

The pooled prevalence of MetS was estimated based on the three diagnostic methods (IDF, ATP III and de Ferranti). A total of 14 articles [35, 47, 55, 58, 63, 69, 72, 77, $79,87-89,92,95]$ were eligible to compute the pooled prevalence of MetS in the IDF criteria. Accordingly, $24.1 \%$ ( $95 \%$ CI $16.90,31.29, \mathrm{I}^{2}=96.6 \%$ ) of the study subjects were found to have MetS. Abdominal obesity was the most common (60.9\%) component of MetS, whereas high FG level was the least (10.3\%) component. According to the modified ATP III, the pooled prevalence of MetS was $36.51 \%$ (95\% CI $-1.76,74.78, \mathrm{I}^{2}=99.8 \%$ ). It was computed using eight articles $[50,57,63,71,77$, $84,89,104]$. Two thirds $(67.2 \%)$ of the children and adolescents were found to have abdominal obesity, but very few (3.4\%) of them had high FG level. Besides, only two articles $[89,91]$ were eligible to estimate the pooled prevalence of MetS (56.32\%, 95\% CI 22.34, 90.29, $\mathrm{I}^{2}=94.4 \%$ ) among overweight and/or obese children and adolescents in accordance with de Ferranti criteria. Similarly, abdominal obesity and high FG level were the most (91.2\%) and least $(7.75 \%)$ components of MetS in the de Ferranti diagnostic criteria.

The pooled prevalence of MetS was also computed based on gender. The prevalence of MetS was relatively higher in males $(26.63 \%)$ than females $(24.05 \%)$ in the IDF method. Likewise, males (33.37\%) were highly affected by MetS than females (31.4\%) according to the modified ATP III diagnostic criteria (Fig. 2 \& Table 4).

\section{Prevalence of MetS \& components in the general population of children \& adolescents}

The pooled prevalence of MetS was estimated in LMICs using the IDF, ATP III and de Ferranti diagnostic methods. A total of 30 [33, 36-38, 40-44, 46, 48, 51, 52, 54, 


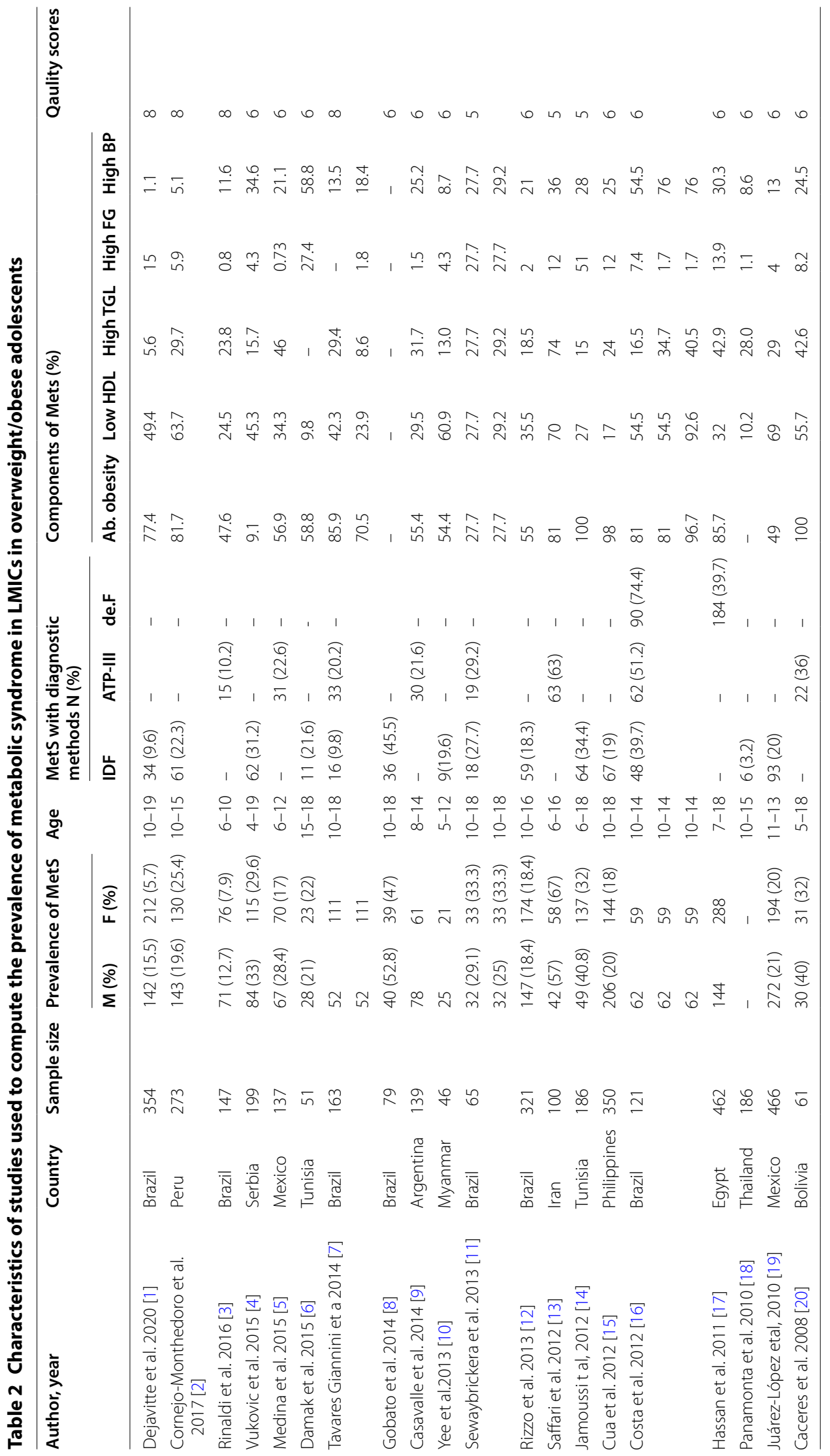




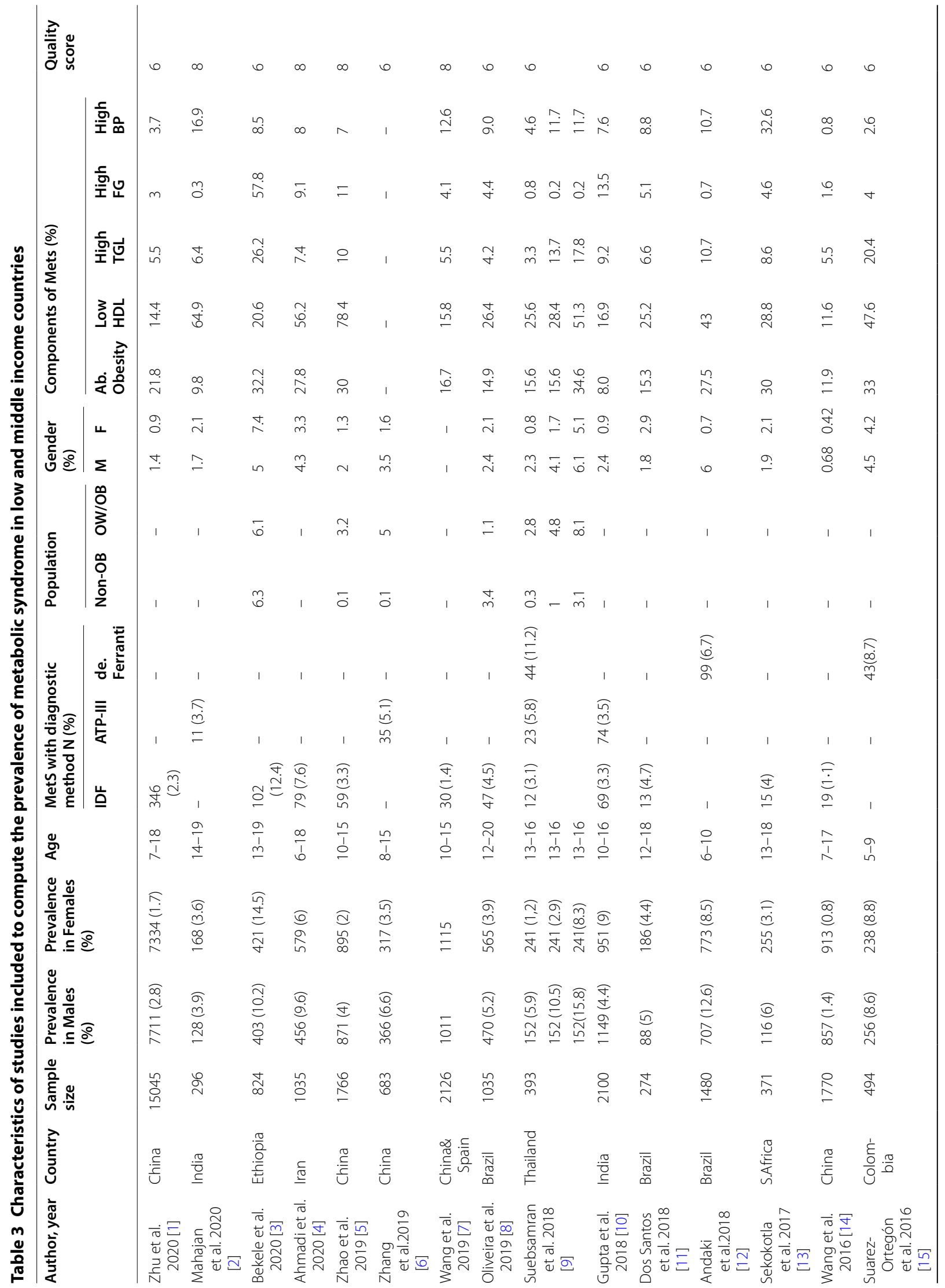




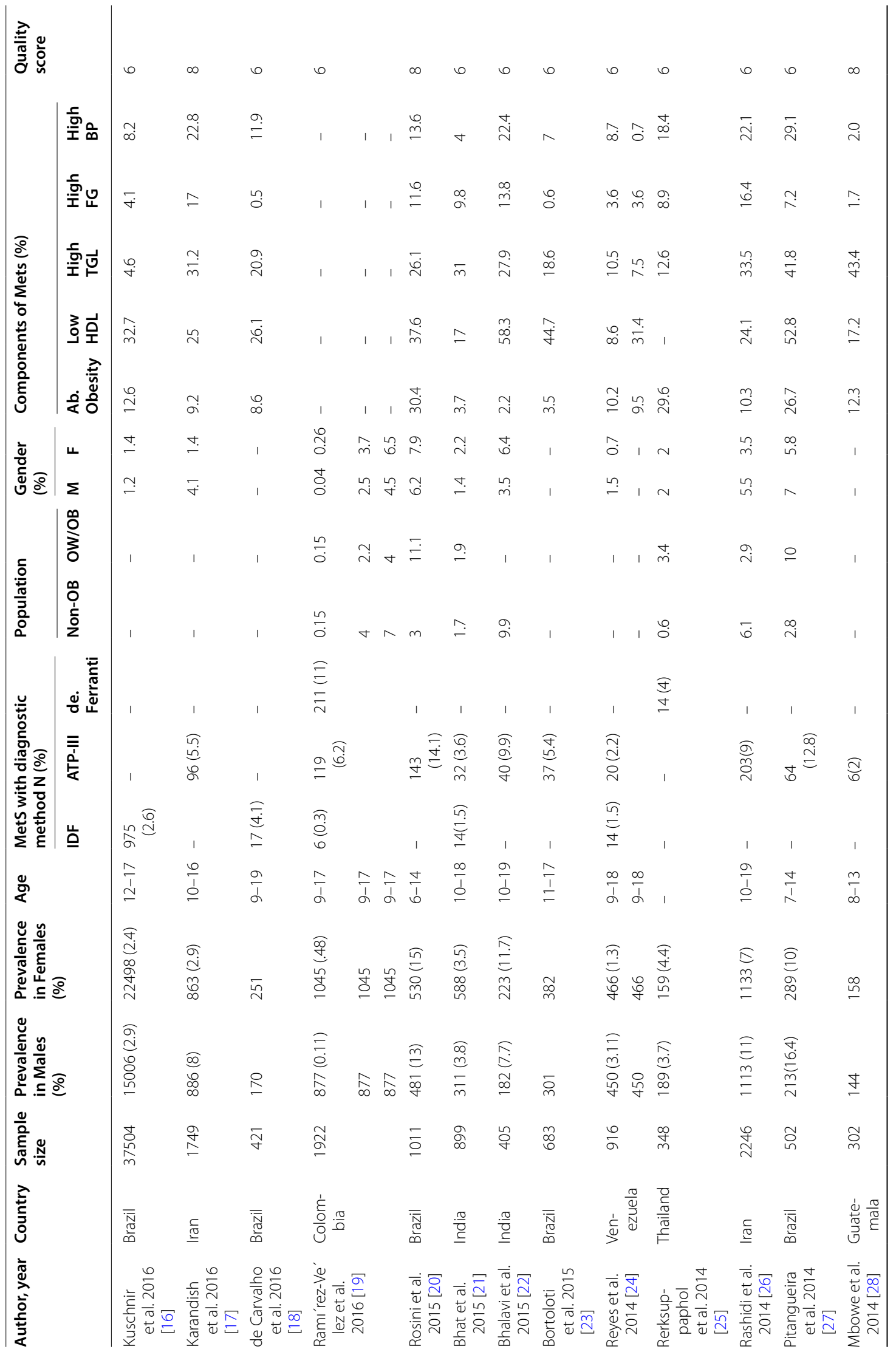




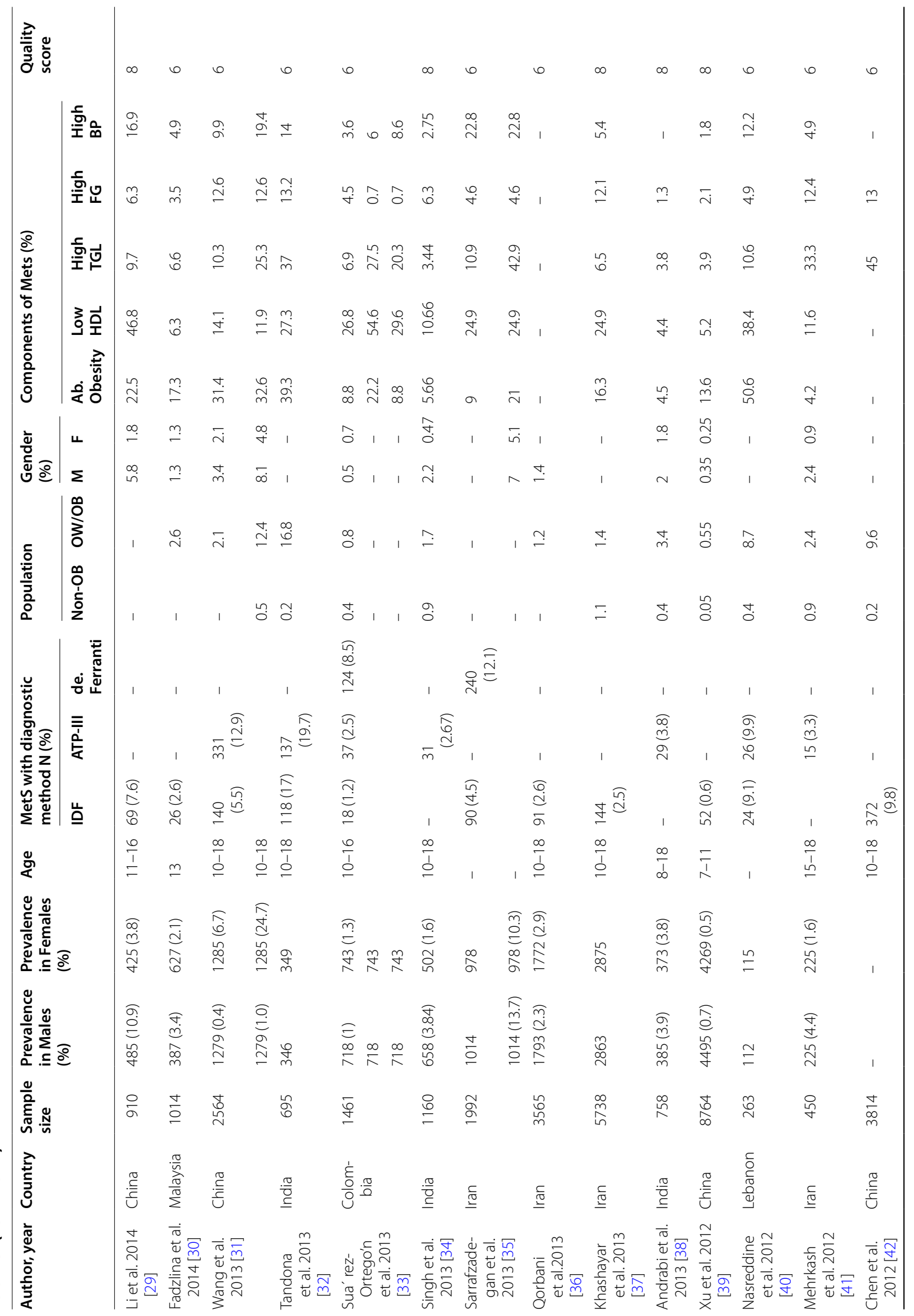




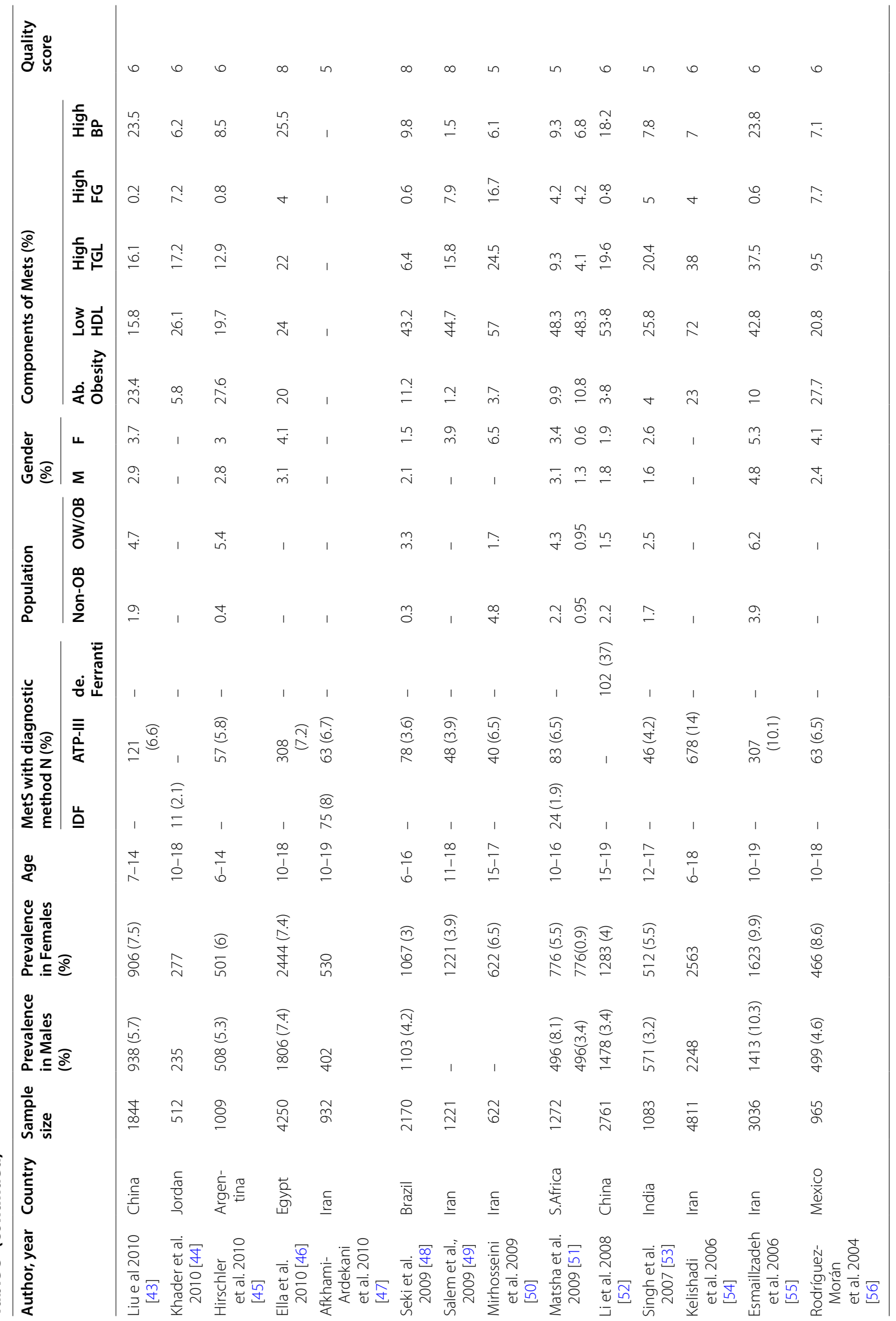


$60,62,68,70,73-75,78,80,81,83,85,90,94,98,102]$, $33[34,39,42,43,51,53,56,59-62,65-67,73-76,82$, $85,86,93,96-102,105-108]$, and 8 [42, 45, 49, 51, 64, $75,78,103]$ articles were eligible to compute the pooled estimates in the IDF, ATP III and de Ferranti diagnostic criteria, respectively.

According to the IDF criteria, the pooled prevalence of MetS among the general population of children and adolescents was $3.98 \%$ (95\% CI 3.35, 4.61, $\mathrm{I}^{2}=97.8 \%$ ). The pooled estimate in males $(3.46 \%$; $95 \%$ CI $2.69,4.23$, $\left.\mathrm{I}^{2}=97.6 \%\right)$ was relatively higher than females $(2.99 \%$; $95 \%$ CI 2.34, 3.65, $\left.\mathrm{I}^{2}=95.6 \%\right)$. From the components, low HDL-C level was the commonest (27.93\%) and high FG (7.78\%) was the infrequent one.

Similarly, 6.71\% (95\% CI 5.51, 7.91, $\mathrm{I}^{2}=97.6 \%$ ) study subjects were found to have MetS in the ATP III criteria. MetS among males (6.24\%; 95\% CI 4.89, 7.59, $\left.\mathrm{I}^{2}=93.9 \%\right)$ and females $\left(6.51 \%\right.$; $95 \%$ CI $\left.4.99,8.03, \mathrm{I}^{2}=95.8 \%\right)$ was nearly the same. Low HDL-C was seen in one third (31.3\%; 95\% CI 23.89, 38.72, $\left.\mathrm{I}^{2}=99.7 \%\right)$ of study subjects and high FG in $6.1 \%$ (95\% CI 5.02, 7.15, $\left.\mathrm{I}^{2}=98.7 \%\right)$ of study subjects.

Besides, the pooled prevalence of MetS in children and adolescents with de Ferranti diagnostic method was 8.19\% (95\% CI 5.58, 10.79, $\mathrm{I}^{2}=96.2 \%$ ) with similar prevalence in males $\left(8.78 \%\right.$; 95\% CI 5.45, 12.12, $\left.\mathrm{I}^{2}=94.3 \%\right)$ and females (8.51\%; 95\% CI 5.21, $\left.11.75, \mathrm{I}^{2}=93.7 \%\right)$. The pooled estimate of low HDL-C was $45.83 \%$ (95\% CI $\left.34.53,57.14, \mathrm{I}^{2}=99.1 \%\right)$, the highest, and only $2.12 \%(95 \%$ CI $\left.1.15,3.08, \mathrm{I}^{2}=94.7 \%\right)$ of the population had a high FG level (Fig. 3 \& Table 5).

\section{Subgroup analysis of the pooled prevalence of MetS in the general population}

The subgroup analyses were performed for the two diagnostic methods (IDF and ATP III) using the two parameters (income level and continent). In the IDF diagnostic method, the pooled estimate of MetS in LIE, LMIE and UMIE countries were estimated. The prevalence of MetS in LIEs $(12.4 \%, 95 \%$ CI 10.5, 14.65) was computed from one study. Likewise, the pooled estimates of MetS in LMIE (6.91\%; 95\% CI 2.35, 11.46, $\left.\mathrm{I}^{2}=98.2 \%\right)$ and $\operatorname{UMIE}\left(3.51 \% ; 2.88,4.14, \mathrm{I}^{2}=97.7 \%\right)$ countries were computed from three and 26 articles, respectively. Regarding the continent where the original studies were conducted, only three articles were from Africa, seven articles from Latin America and the majorities (20) articles were from Asia. The pooled prevalence of MetS in Africa, Asia and Latin America were $6.03 \%$ (95\% CI 0.24, 11.28, I $\left.\mathrm{I}^{2}=94.7 \%\right)$, 4.39\% (95\% CI $3.50,5.29, \mathrm{I}^{2}=98 \%$ ), and $2.46 \%$ (95\% CI 1.29, 3.64, $\mathrm{I}^{2}=97.8 \%$ ), respectively (Fig. 4 ).
According to the ATP III diagnostic method, the pooled prevalence of MetS in countries classified under LMIE and UMIE was estimated from eight and 25 eligible articles, respectively. Accordingly, 5.73\% (95\% CI $\left.3.72,7.74, \mathrm{I}^{2}=95.9 \%\right)$ of the study subjects in LMIEs and $7 \%\left(95 \%\right.$ CI $\left.5.53,8.48, \mathrm{I}^{2}=96.8 \%\right)$ in UMIE countries were found to have MetS. The pooled prevalence of MetS in Africa, Latin America and Asia was computed from two, eight and 23 articles, respectively. Thus, $6.71 \%$ (95\% CI 5.51, 7.91, $\left.\mathrm{I}^{2}=0.00 \%\right)$ in Africa, $5.19 \%\left(95 \%\right.$ CI 3.31, 7.05, $\left.\mathrm{I}^{2}=95.3 \%\right)$ in Latin America and $7.24 \%\left(95 \%\right.$ CI 5.64, 8.84\%, $\left.\mathrm{I}^{2}=96.9 \%\right)$ in Asia had MetS (Fig. 5).

\section{Publication bias and sensitivity analysis}

Due to the presence of high heterogeneity among the included articles, the possible sources of variation were further explained. Thus, the funnel plots for both IDF and ATP III diagnostic criteria were presented (Fig. 6). The asymmetry of plots was objectively verified by Egger's regression test and there was publication bias among the articles included in computing the pooled prevalence of MetS in the IDF criteria $(P=0.001)$, whereas the Egger's regression test revealed that there was no publication bias in the pooled estimate of ATP III diagnostic criteria $(\mathrm{P}=0.063)$. Moreover, sensitivity analysis was computed for both diagnostic methods. This was done to evaluate if the pooled estimates were altered by the exclusion of any single study. However, none of the studies had significant effects in the pooled estimates (Fig. 7).

Finally, the prevalence of MetS in LMICs among the general population children and adolescents was plotted in linear graph using the number of cases with publication year (2004 to 2020). The graph depicted that there is an increasing trend in the two diagnostic methods (IDF \& de Ferranti) and the reverse was true in ATP III criteria (Fig. 8).

\section{Discussion}

To the authors' knowledge, this is the first comprehensive systematic review and meta-analysis, determining the prevalence of metabolic syndrome among children and adolescents in LMICs. In this study, the pooled prevalence of MetS was computed using three diagnostic methods: IDF, ATP III \& de Ferranti. Seventy six articles with 142,142 participants were included in this metaanalysis. Of the total studies, 56 were conducted among the general population of study subjects, and 20 were conducted among overweight and/or obese children and adolescents.

The current meta-analysis revealed that the prevalence of MetS among overweight and obese population 
Study

ID

Dejavitte et al,2020

Cornejo-Monthedoro et $\mathrm{al}_{2}, 2017$

Vukovic et al, 2015

Damak et al, 2015

Tavares Giannini et a, 2014

Gobato et al, 2014

Yee et al, 2013

Sewaybrickera et al, 2013

Rizzo et 1,2013

Jamoussi $t$ al, 2012

Cua et al, 2012

Costa et al, 2012

Panamonta et al, 2010

Juárez-López etal, 2010

Overall (I-squared $=96.6 \%, p=0.000$ )

NOTE: Weights are from random effects analysis

$\begin{array}{ll} & \\ \text { Study } & -68.7\end{array}$

ID

\section{IDF}

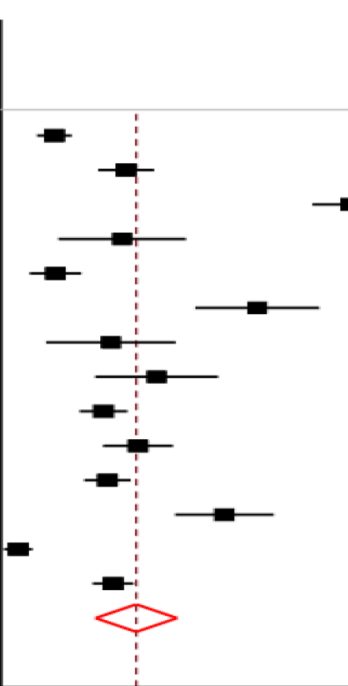

ES $(95 \% \mathrm{Cl})$

$9.60(6.52,12.68)$

$22.30(17.36,27.24)$

- $62.00(55.26,68.74)$

$21.60(10.31,32.89)$

$9.80(5.23,14.37)$

$45.50(34.52,56.48)$

$19.60(8.13,31.07)$

$27.70(16.82,38.58)$

$18.30(14.07,22.53)$

$24.40(18.23,30.57)$

$19.00(14.88,23.12)$

$39.70(30.98,48.42)$

$3.20(0.67,5.73)$

$20.00(16.37,23.63)$

$24.09(16.90,31.29)$

Rinaldi et al, 2016

Medina et al, 2015

Tavares Giannini et a, 2014

Casavalle et al, 2014

Sewaybrickera et al, 2013

Saffari et al, 2012

Costa et al, 2012

Caceres et al, 2008

Overall (I-squared $=99.8 \%, p=0.000)$

ATP III

ES $(95 \% \mathrm{CI})$

$10.20(5.30,15.10)$

$22.60(15.60,29.60)$

$20.20(14.05,26.35)$

$21.60(14.76,28.44)$

$29.20(18.15,40.25)$

- 99.90 (99.27, 100.53)

$52.20(43.30,61.10)$

$36.00(23.95,48.05)$

$36.51(-1.76,74.78)$

NOTE: Weights are from random effects analysis

\begin{tabular}{lll}
\hline & 1 \\
Study & -101
\end{tabular}

o

101

ID

de Ferranti

ES (95\% CI)

Costa et al, 2012

Hassan et al, 2011

Overall (I-squared $=94.4 \%, \mathrm{p}=0.000$ )

NOTE: Weights are from random effects analysis

$-90.3$

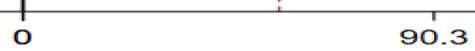

$74.40(59.31,89.49)$

$39.70(34.02,45.38)$

$56.32(22.34,90.29)$

Fig. 2 The pooled prevalence of MetS in overweight and obese children and adolescents 
Table 4 Pooled prevalence of MetS \& components in overweight \& Obese children and adolescents

\begin{tabular}{|c|c|c|c|c|c|}
\hline Variables & Characteristics & \# of studies & Pooled prevalence, $(95 \% \mathrm{Cl})$ & $\begin{array}{l}\text { Heterogeneity } \\
\left.\left(I^{2}(\%), \text { P-value }\right)\right)\end{array}$ & Model \\
\hline \multirow[t]{3}{*}{ Diagnostic Criteria } & IDF & 14 & $24.09(16.90,31.29)$ & $96.6, P \leq 0.001$ & REM \\
\hline & ATP III & 8 & $36.51(-1.76,74.78)$ & $99.8, P \leq 0.001$ & REM \\
\hline & de Ferranti & 2 & $56.32(22.34,90.29)$ & $94.4, P \leq 0.001$ & REM \\
\hline \multirow[t]{5}{*}{ Components of MetS (IDF) } & Abdominal Obesity & 12 & $60.90(46.63,75.16)$ & $99.7, P \leq 0.001$ & REM \\
\hline & Low HDL-C & 13 & $34.83(23.8,46.48)$ & $98.0, P \leq 0.001$ & REM \\
\hline & High TG & 12 & $18.59(13.21,23.98)$ & 93.0, $P \leq 0.001$ & REM \\
\hline & High FG & 13 & $10.27(6.67,13.87)$ & $95.9, P \leq 0.001$ & REM \\
\hline & Elevated BP & 13 & $23.88(17.29,30.47)$ & $99.8, P \leq 0.001$ & REM \\
\hline \multirow[t]{5}{*}{ Components of MetS (ATPIII) } & Abdominal Obesity & 8 & $67.20(49.45,84.95)$ & $98.9, P \leq 0.001$ & REM \\
\hline & Low HDL-C & 8 & $42.48(33.45,51.51)$ & $99.8, P \leq 0.001$ & REM \\
\hline & High TG & 8 & $38.85(27.61,50.10$ & $92.9, P \leq 0.001$ & REM \\
\hline & High FG & 7 & $3.39(1.05,5.74)$ & $81.4, P \leq 0.001$ & REM \\
\hline & Elevated BP & 8 & $29.56(15.03,44.8)$ & $96.9, P \leq 0.001$ & REM \\
\hline \multirow[t]{5}{*}{ Components of MetS (de Ferranti) } & Abdominal Obesity & 2 & $91.20(80.42,101.98)$ & $95.6, P \leq 0.001$ & REM \\
\hline & Low HDL-C & 2 & $62.29(2.91,121.68)$ & $99.7, P \leq 0.001$ & REM \\
\hline & High TG & 2 & $42.40(38.39,46.40)$ & $0.00, P=0.632$ & FEM \\
\hline & High FG & 2 & $7.75(-4.20,19.71)$ & $97.3, P \leq 0.001$ & REM \\
\hline & Elevated BP & 2 & $53.04(8.25,97.82)$ & $99.1, P \leq 0.001$ & REM \\
\hline \multirow[t]{2}{*}{ Gender (IDF) } & Male & 10 & $26.63(23.95,29.31)$ & $99.3, P \leq 0.001$ & REM \\
\hline & Female & 10 & $24.05(16.65,31.45)$ & $90.7, P \leq 0.001$ & REM \\
\hline \multirow[t]{2}{*}{ Gender (ATPIII) } & Male & 5 & $33.37(19.68,47.06)$ & $99.5, P \leq 0.001$ & REM \\
\hline & Female & 5 & $31.40(15.43,47.36)$ & $99.8, P \leq 0.001$ & REM \\
\hline
\end{tabular}

REM, random effect model; FEM, fixed effect model

is remarkably higher than the general population of children and adolescents. The pooled prevalence of MetS in the overweight and obese children and adolescents is as follows: IDF: $24.1 \%$, ATP III: $36.5 \%$ and de Ferranti: $56.32 \%$. Whereas, it is $3.98 \%, 6.71 \%$ and $8.19 \%$ with the IDF, ATP III and de Ferranti diagnostic methods, respectively in the general population. The prevalence in the general population is comparable with a review done in Iran, where the prevalence of MetS was $0-8 \%, 3-16 \%$, and $0-22 \%$ in the IDF, ATP III and de Ferranti criteria, respectively [18]. However, the current prevalence among the overweight and obese population is considerably higher than the Iranian review findings [18]. The possible explanation for this variation could be due to the fact that overweight and obese children are at greater risk of developing metabolic syndrome as compared to children with normal weight [20]. The present findings are also in line with the previous review findings which reported that the prevalence of MetS in the pediatric population ranged from $1.2-22.6 \%$ [109] to $0-19.2 \%$ [15] irrespective of the specific diagnostic methods. The median prevalence of MetS in the world was 3.3\% in 2007 to 2009 , which is lower than the all pooled estimates in this meta-analysis [15]. The prevalence of MetS is also considerably higher than a meta-analysis findings done in Chinese children and adolescents, where $1.8 \%$ (IDF) and $2.6 \%$ (ATP III) were found to have MetS [110]. This implies that MetS is increasing throughout the world, including in LMICs and it is supported by the previous reviews $[14,111,112]$.

Regarding gender based distribution; the prevalence of MetS in males is relatively higher than in females in most of the diagnostic methods. The prevalence among overweight and obese males is $26.63 \%$ (IDF) and $33.37 \%$ (ATP III), and it is $24.05 \%$ (IDF) and $31.4 \%$ (ATPIII) among females. Similarly, the prevalence of MetS among males (3.46\%) in the general population is higher as compared to females (2.99\%) with IDF criteria. However, the pooled prevalence of MetS among males and females in the general population of children and adolescents is approximately similar in the two diagnostic methods (ATPIII \& de Ferranti). The prevalence in males is $6.24 \%$ (ATPIII) and $8.78 \%$ (de Ferranti); and it is $6.51 \%$ (ATPIII) and $8.51 \%$ (de Ferranti) among females. In general, males are at greater risk to have MetS than females. This finding is supported by most of the original studies included in this meta-analysis and the other meta-analysis done in china [110]. The possible justification for gender disparities 


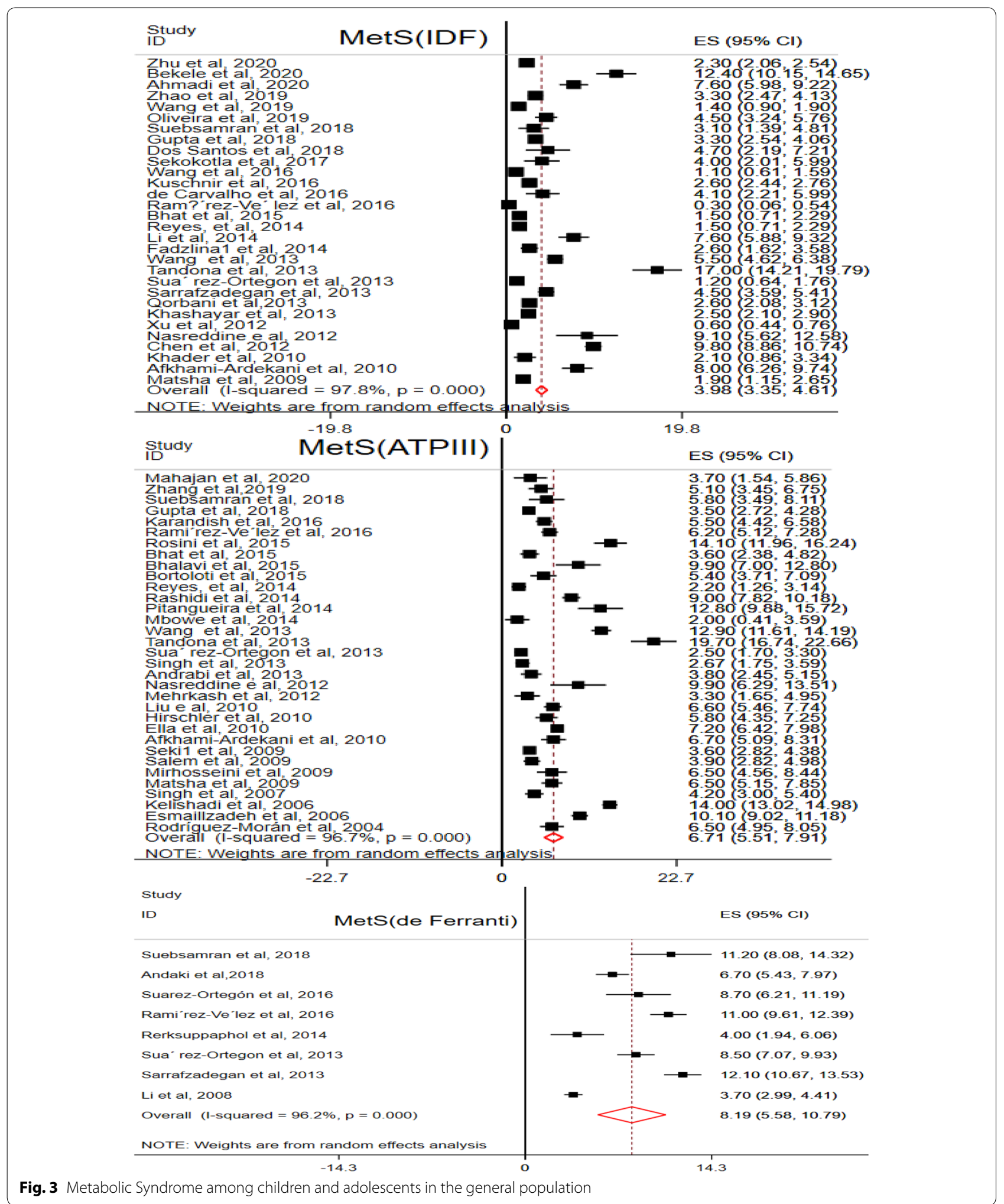


Table 5 The pooled prevalence of MetS and components in the general population

\begin{tabular}{|c|c|c|c|c|c|}
\hline Variables & Characteristics & $\begin{array}{l}\text { \# included } \\
\text { articles }\end{array}$ & Pooled prevalence $(95 \%, \mathrm{Cl})$ & $\begin{array}{l}\text { Heterogeneity }\left(I^{2}\right. \\
(\%), \text { P-value) }\end{array}$ & Model \\
\hline \multirow[t]{3}{*}{ Diagnostic Criteria } & IDF & 30 & $3.98(3.35,4.61)$ & $97.8, P \leq 0.001$ & REM \\
\hline & ATP III & 33 & $6.71(5.51,7.91)$ & $96.7, P \leq 0.001$ & REM \\
\hline & de F & 8 & $8.19(5.58,10.79)$ & $96.2, P \leq 0.001$ & REM \\
\hline \multirow[t]{2}{*}{ Gender distribution of MetS (IDF) } & Male & 20 & $3.46(2.69,4.23)$ & $96.7, P \leq 0.001$ & REM \\
\hline & Female & 20 & $2.99(2.34,3.65)$ & $95.6, P \leq 0.001$ & REM \\
\hline \multirow[t]{2}{*}{ Gender distribution of MetS (ATPIII) } & Male & 24 & $6.24(4.89,7.59)$ & $93.9, P<0.001$ & REM \\
\hline & Female & 26 & $6.51(4.99,8.03)$ & $95.8, P \leq 0.001$ & REM \\
\hline \multirow[t]{2}{*}{ Gender distribution of MetS (deF.) } & Male & 7 & $8.78(5.45,12.12)$ & $94.3, P \leq 0.001$ & REM \\
\hline & Female & 7 & $8.51(5.21,11.75)$ & $93.7, P \leq 0.001$ & REM \\
\hline \multirow[t]{2}{*}{ Study Population (IDF) } & Overweight \& Obese & 11 & $1.48(0.94,2.01)$ & $87.8, P \leq 0.001$ & REM \\
\hline & Others $^{\mathrm{a}}$ & 12 & $0.58(0.33,0.82)$ & $93.2, P \leq 0.001$ & REM \\
\hline \multirow[t]{2}{*}{ Study Population (ATP III) } & Overweight \& Obese & 18 & $4.66(3.49,5.83)$ & $95.7, P \leq 0.001$ & REM \\
\hline & Others & 19 & $2.31(1.53,2.72)$ & $95.7, P \leq 0.001$ & REM \\
\hline \multirow[t]{2}{*}{ Study Population (de F.) } & Overweight \& Obese & 4 & $3.95(1.82,6.08)$ & $93.3, P \leq 0.001$ & REM \\
\hline & Others $^{\mathrm{a}}$ & 4 & $3.20(0.78,5.62)$ & $96.4, P \leq 0.001$ & REM \\
\hline \multirow[t]{5}{*}{ Components MetS (IDF) } & Abdominal obesity & 25 & $18.85(16.39,21.31)$ & $98.9, P \leq 0.001$ & REM \\
\hline & Low HDL-C & 25 & $27.93(21.91,33.96)$ & $99.8, P \leq 0.001$ & REM \\
\hline & High TG & 26 & $11.09(9.13,13.05)$ & $99.3, P \leq 0.001$ & REM \\
\hline & High FG & 26 & $7.78(6.40,9.15)$ & $99.0, P \leq 0.001$ & REM \\
\hline & Elevated BP & 25 & $8.76(7.22,10.29)$ & $99.1, P \leq 0.001$ & REM \\
\hline \multirow[t]{5}{*}{ Components MetS (ATP III) } & Abdominal obesity & 18 & $4.66(3.49,5.83)$ & $95.7, P \leq 0.001$ & REM \\
\hline & Low HDL-C & 28 & $31.30(23.89,38.72)$ & $99.7, P \leq 0.001$ & REM \\
\hline & High TG & 28 & $21.05(16.63,25.48)$ & $99.4, P \leq 0.001$ & REM \\
\hline & High FG & 28 & $6.08(5.02,7.15)$ & $98.7, P \leq 0.001$ & REM \\
\hline & Elevated BP & 27 & $12.27(9.39,15.16)$ & $99.1, P \leq 0.001$ & REM \\
\hline \multirow[t]{5}{*}{ Components MetS (de F.) } & Abdominal obesity & 7 & $22.65(14.01,31.39)$ & $99.3, P \leq 0.001$ & REM \\
\hline & Low HDL-C & 6 & $45.83(34.53,57.14)$ & $99.1 P \leq 0.001$ & REM \\
\hline & High TG & 7 & $17.4(12.24,21.84)$ & $97.3 P \leq 0.001$ & REM \\
\hline & High FG & 7 & $2.12(1.15,3.08)$ & $94.7, P \leq 0.001$ & REM \\
\hline & Elevated BP & 7 & $12.86(7.11,18.61)$ & $98.7, P \leq 0.001$ & REM \\
\hline
\end{tabular}

a Others: underweight and normal weight, REM, Random Effect Model; de F., de Ferranti

could be related to higher prevalence of obesity in males than females. This could be further explained by the fact that males usually consume excessive energy due to self and family perceived underweight and underestimation of their weight. On the contrary, female adolescents control their weight through diet and physical activity due to self-perceived overweight [113]. But, further exploration is needed with experimental studies.

The pooled prevalence of the components of MetS was also computed in each of the diagnostic methods and considerable numbers of study subjects were found to have each of the five components. Abdominal obesity is found to be the commonest component of MetS in overweight and obese children, with a pooled prevalence of 60.9\% (IDF), 67.2\% (ATP III), and 91.2\% (de Ferranti). In contrary, a high FG level was the most infrequent component of MetS with a pooled prevalence of $10.3 \%$ (IDF),
3.4\% (ATP III), and 7.75\% (de Ferranti). Besides, the pooled prevalence of low HDL-C is the most prevalent component of MetS among the general population. It was found in $27.93 \%$ (IDF), 31.3\% (ATP III) and $45.83 \%$ (de Ferranti) of the study population. But, high FG is the least component in IDF $(7.78 \%)$ and de Ferranti $(2.12 \%)$ criteria. Likewise, abdominal obesity is the least $(4.46 \%)$ component in the ATP III criteria. All the other component of MetS in overweight and obese children is considerably higher as compared to the pooled prevalence in the general population. The possible elucidation could be due to a multitude of factors like consumption of unhealthy diets (Western type of diets), diets low in fruit, vegetables, fruits and grains $[114,115]$.

Moreover, children and adolescents from countries with UMIEs are found to have a lower risk of developing MetS than children from countries classified under LIE 


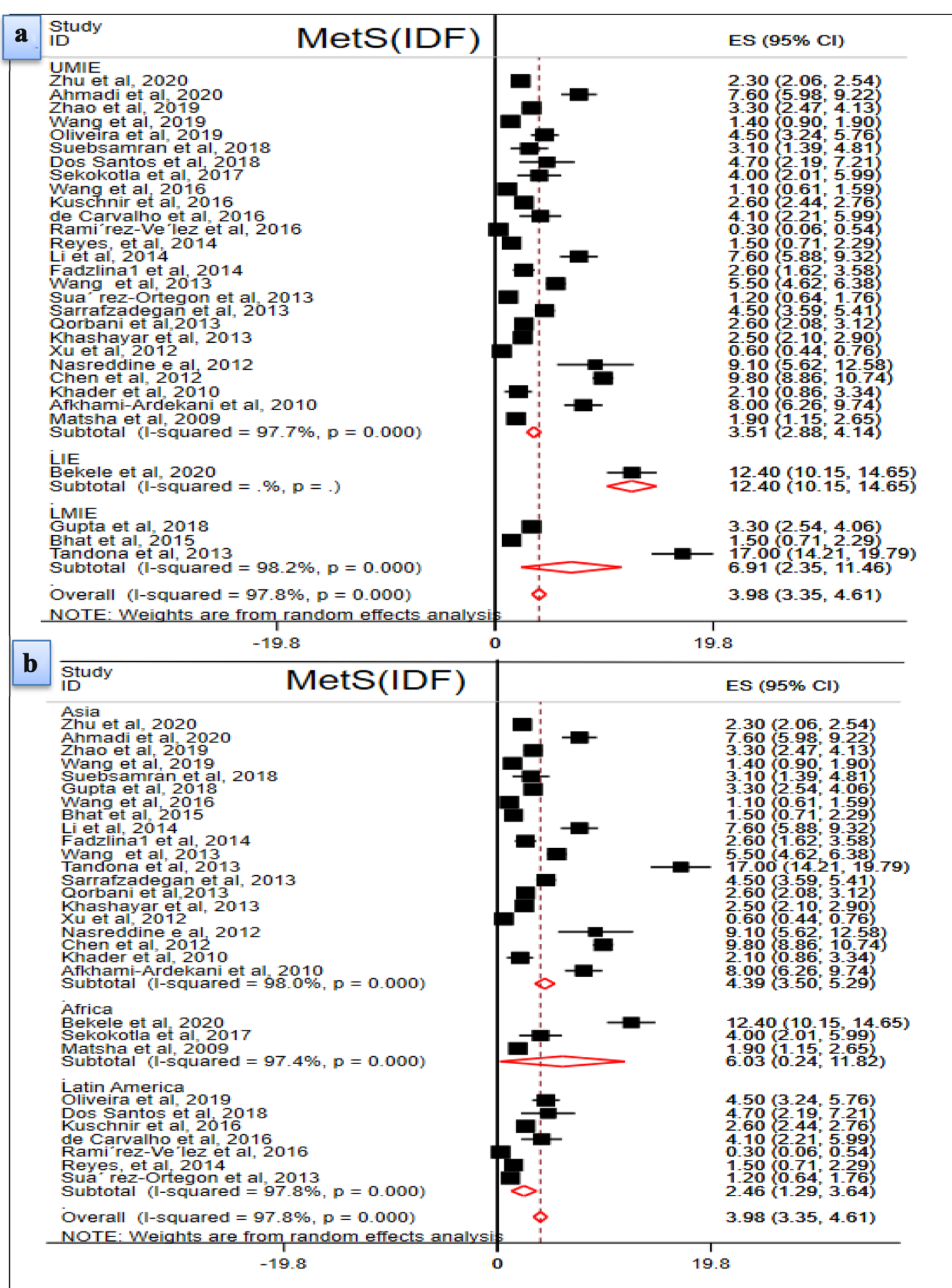

Fig. 4 Pooled prevalence of MetS (a Subgroup analysis using income level; b Subgroup analysis based on continent) 


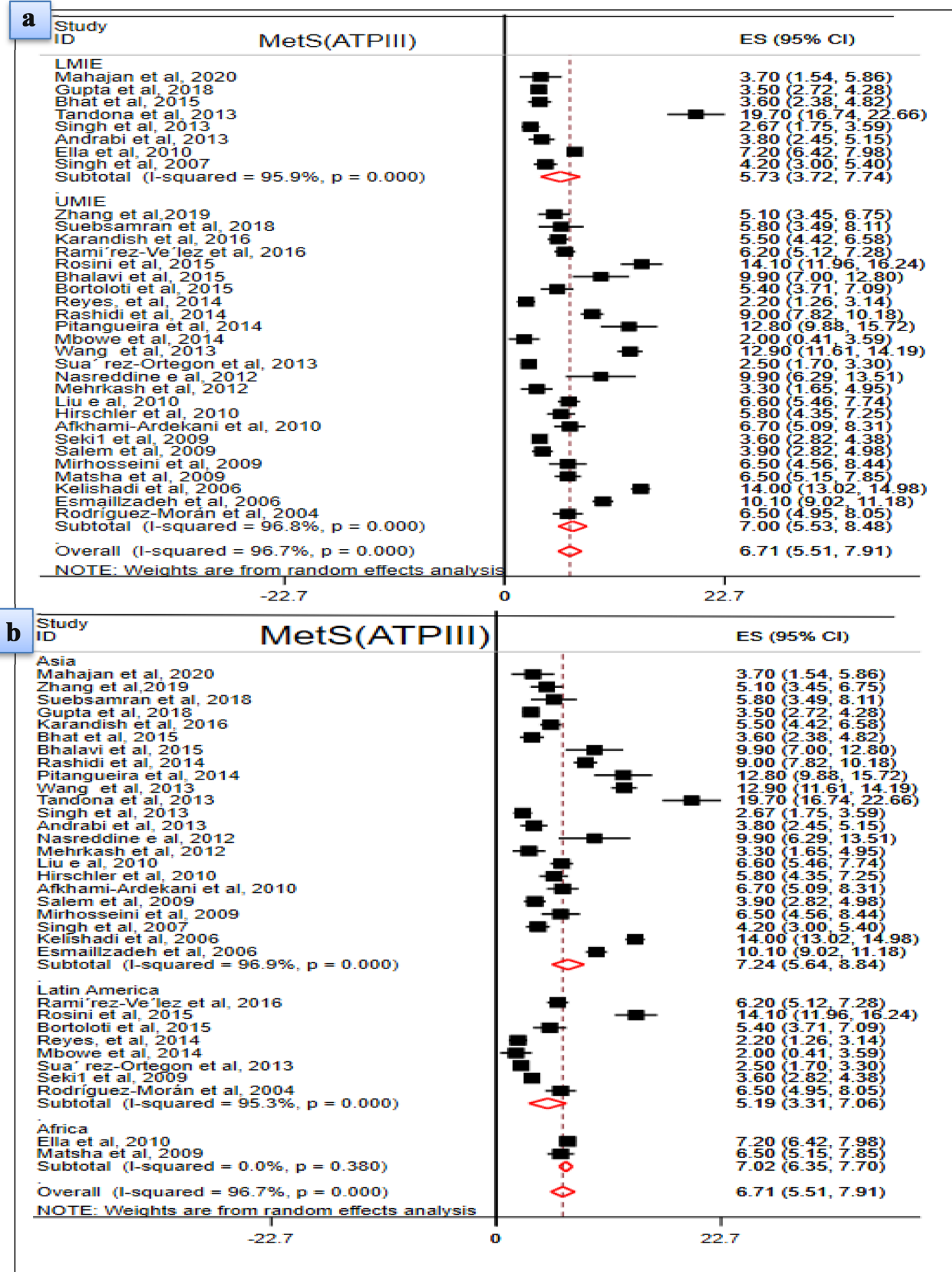

Fig. 5 Pooled prevalence of MetS (a Subgroup analysis using income level; b Subgroup analysis using continent) 


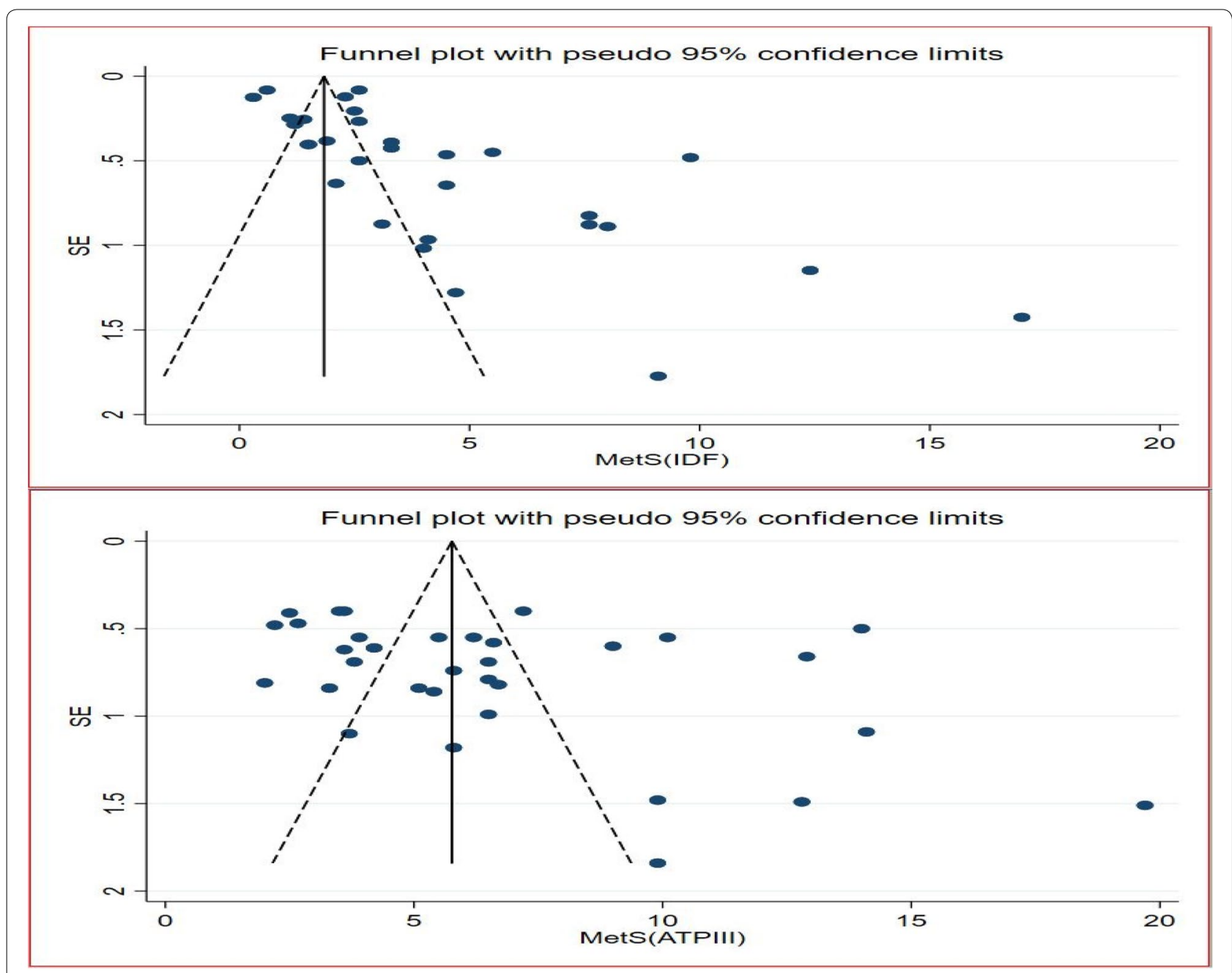

Fig. 6 Funnel plot for the two diagnostic methods (IDF \& ATP III)

and LMIE in the IDF criteria. The pooled prevalence of MetS in LIE, LMIE, and UMIE countries is $12.4 \%, 6.91 \%$ and $12.4 \%$, respectively. However, the prevalence of MetS in LMIE (5.3\%) is relatively lower than UMIE (7\%) countries in ATP III diagnostic criteria. These findings remind that MetS is an emerging crisis in children and adolescent without geographical boundary. This could be primarily associated with the nutrition transition in developing countries [116].

In addition, MetS was calculated based on the continent where the original studies were conducted. In the IDF criteria, the pooled prevalence in Africa (6.03\%) is relatively higher than in Asia (4.39\%) and Latin America $(2.46 \%)$. Whereas, the pooled prevalence of MetS in Africa (7.02\%) and Asia (7.24\%) are nearly the same in the general population and higher than the prevalence in Latin America (5.19\%) in the ATP III diagnostic criteria. The rising burden of MetS in the poor continents like Africa is corroborated by the fact that the universal increment of obesity, the main predictor of MetS in the world, including the poorest LMICs [117, 118]. Finally, the number of cases was plotted against the publication year. It was pinpointed in the line graph that there is an increasing trend in the two diagnostic methods (IDF and de Ferranti), but the trend decreases from 2004 to 2020 in the ATP III diagnostic method. This may be attributed to differences in the sample size. The other possible rational could be related to variation in the year of publication of the original studies.

The findings of this study will have a vital implication for program planners and policy makers to design preventive strategies accordingly. These findings will have several implications for the poorest LMICs, where nutrition transition and the triple burden of malnutrition are prevailing in recent years. However, the issue of which diagnostic method is the best remains unresolved and 
IDF

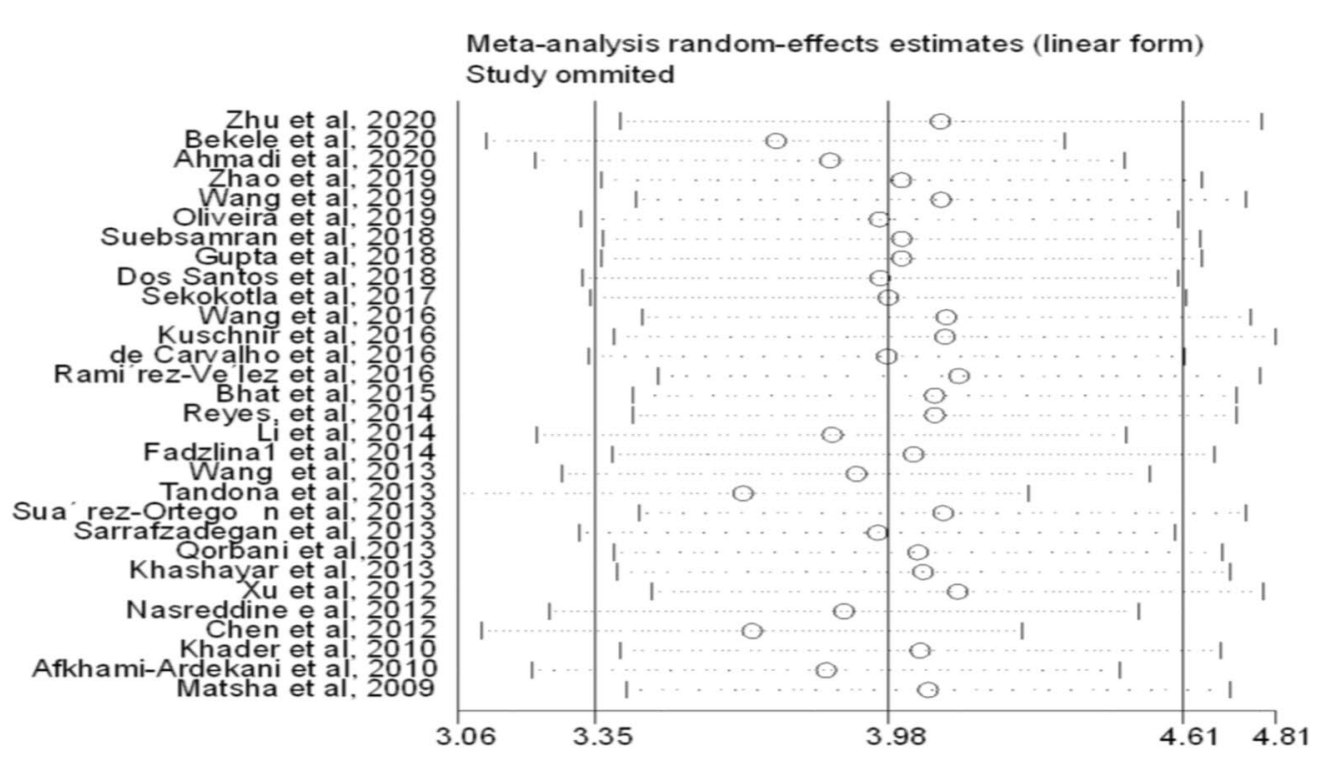

\section{ATP III}

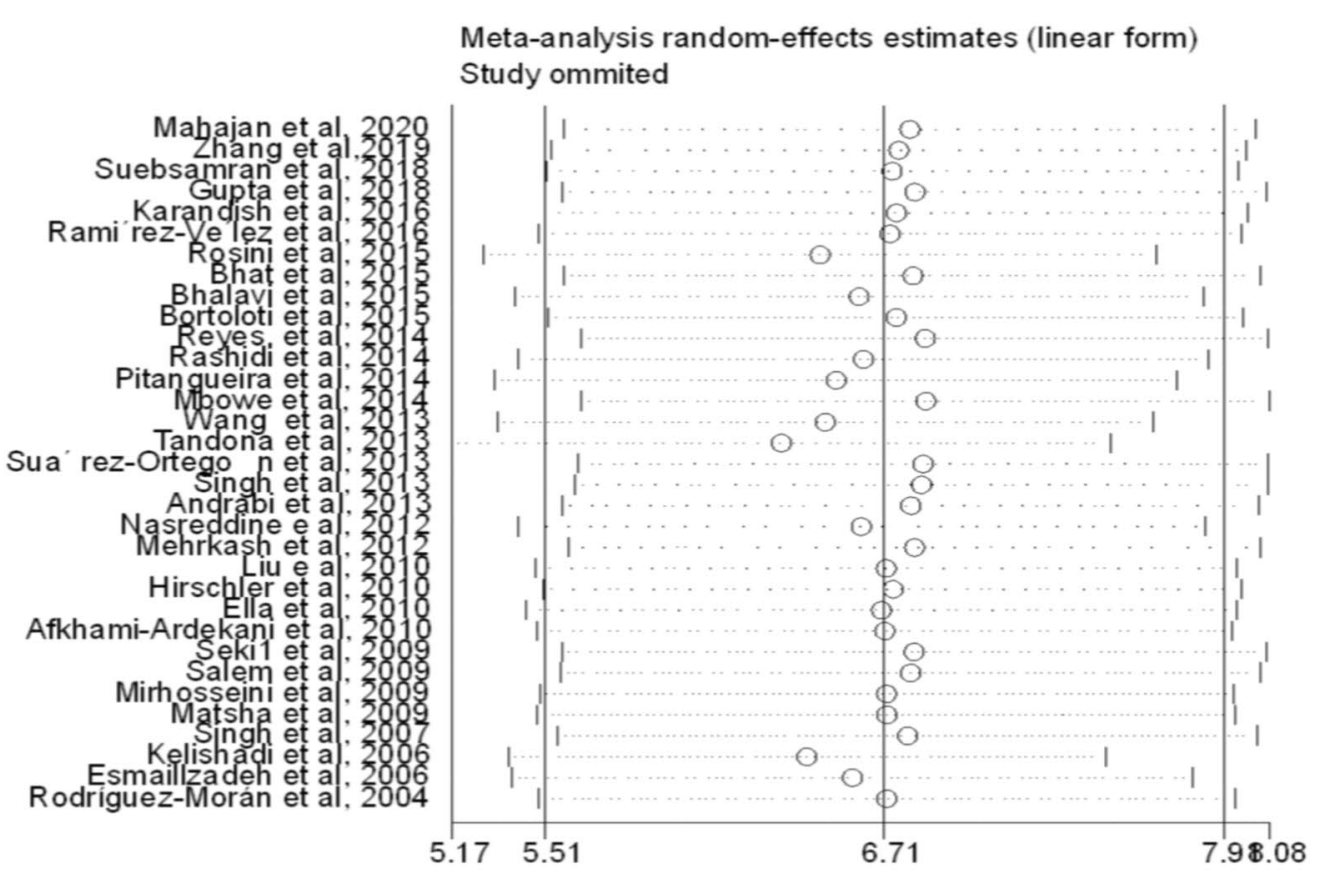

Fig. 7 Sensitivity analysis for two diagnostic methods (IDF \& ATPIII)

this could affect the final conclusion. The other limitation of this study was some articles written other than the English language and articles with the difficulty of accessing the full texts were excluded. We excluded articles which are not written in English because it is difficult to identify the real estimates of MetS and to assess the qualities of studies. Studies conducted among different population, such as studies among children with 


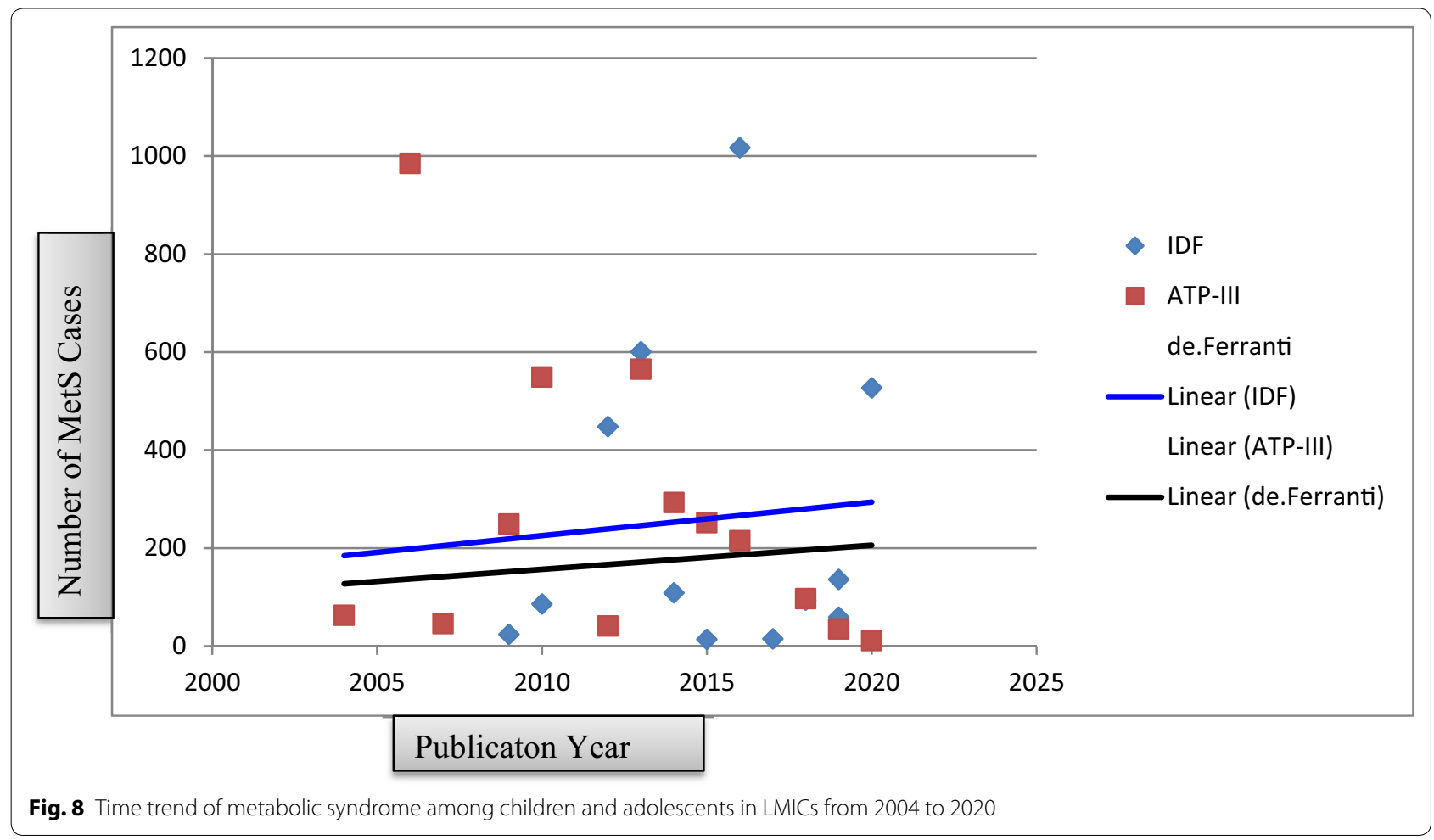

type 1 diabetic were excluded to avoid overestimation of MetS. This could affect the pooled estimates of MetS and components.

\section{Conclusion}

In conclusion, this study illustrates that MetS among children and adolescents is an emerging public health challenge in LMICs where the prevalence of obesity is on the move. The prevalence is significantly higher among the overweight and obese population. The burden is also rising in low income countries found in Asia and Africa. Metabolic syndrome was diagnosed in underweight, normal weight, overweight and obese children and adolescents, revealing the triple burden of malnutrition in these countries. Thus, additional studies need to be conducted to identify all possible factors. Preventive strategies like community based and school based interventions on lifestyle modifications may avert MetS in LMICs. Specifically, promoting healthy eating behaviors and physical activities as well as avoiding consumption of fructose based drinks may primarily decrease the burden.

\section{Supplementary information}

Supplementary information accompanies this paper at https://doi. org/10.1186/s13098-020-00601-8.
Additional file 1. Extraction checklist.

Additional file 2. Critical appraisal of the included studies.

Additional file 3. List of excluded studies.

Abbreviations

HDL-C: High density lipoprotein-cholesterol; Mets: Metabolic syndrome; IDF: International Diabetic Federation; TG: Triglyceride; BP: Blood Pressure; FG: Fasting glucose; WHO: World Health Organization; BMI: Body mass index; ATP III: National Cholesterol Education Program (NCEP) Adult Treatment Panel-III; FG: Fasting glucose; WC: Waist circumference; LMICs: Low and Middle Income Countries; NCD: Noncommunicable diseases; LIE: Low Income Economies;

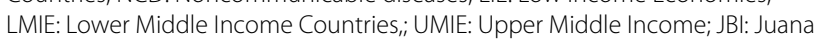
Brigg's Institute.

\section{Acknowledgements}

We are thankful to the authors of original studies included in this systematic review and meta-analysis, and to those who contributed a lot in this work

\section{Authors' contributions}

$Z W B, A A$ and EGA were responsible for analysis, visualization, writing of the manuscript; ZWB, ZT, AA and TW made substantial contributions to data acquisition; ZWB and AA participated in the data interpretation and made substantial revisions in the first draft; ZWB and EGA contributed to the reception and the design of the work. All authors read and approved the final manuscript.

\section{Funding}

Not applicable.

\section{Availability of data and materials}

The data that support the review findings of this study are included in the manuscript and with Additional file 1, 2, 3. 
Ethics approval and consent to participate

Not applicable.

\section{Consent for publication}

Not applicable.

\section{Competing interests}

There are no competing interests.

\begin{abstract}
Author details
1 St. Paul's Hospital Millennium Medical College, Addis Ababa, Ethiopia.

2 Ethipian Public Health Institute, Addis Ababa, Ethiopia. ${ }^{3}$ College of Medicine and Health Sciences, Hawassa University, Hawassa, Ethiopia. ${ }^{4}$ College of Health Science, Debremarkose University, Debre Markos, Ethiopia. ${ }^{5}$ Australian Centre for Public and Population Health Research, School of Public Health, Faculty of Health, University of Technology Sydney, Ultimo, NSW, Australia.

${ }^{6}$ College of Health and Medical Sciences, School of Nursing and Midwifery, Haramaya University, Harar, Ethiopia.
\end{abstract}

Received: 27 August 2020 Accepted: 19 October 2020

Published online: 27 October 2020

\section{References}

1. Third Report of the National Cholesterol Education Program (NCEP) Expert Panel on Detection, Evaluation, and Treatment of High Blood Cholesterol in Adults (Adult Treatment Panel III) final report. Circulation 2002, 106(25):3143-3421.

2. Reaven G. Metabolic syndrome: pathophysiology and implications for management of cardiovascular disease. Circulation. 2002;106(3):286-8.

3. DeBoer MD. Assessing and managing the metabolic syndrome in children and adolescents. Nutrients. 2019;11(8):1788.

4. Morrison JA, Friedman LA, Wang P, Glueck CJ. Metabolic syndrome in childhood predicts adult metabolic syndrome and type 2 diabetes mellitus 25 to 30 years later. J Pediatrics. 2008;152(2):201-6.

5. Muntner P, Srinivasan S, Menke A, Patel DA, Chen W, Berenson G. Impact of childhood metabolic syndrome components on the risk of elevated uric acid in adulthood: the Bogalusa Heart Study. Am J Med Sci. 2008;335(5):332-7.

6. Burgert TS, Taksali SE, Dziura J, Goodman TR, Yeckel CW, Papademetris X, Constable RT, Weiss R, Tamborlane WV, Savoye M, et al. Alanine aminotransferase levels and fatty liver in childhood obesity: associations with insulin resistance, adiponectin, and visceral fat. J Clin Endocrinol Metab. 2006;91(11):4287-94.

7. Coviello AD, Legro RS, Dunaif A. Adolescent girls with polycystic ovary syndrome have an increased risk of the metabolic syndrome associated with increasing androgen levels independent of obesity and insulin resistance. J Clin Endocrinol Metab. 2006;91(2):492-7.

8. Waters KA, Sitha S, O'Brien LM, Bibby S, de Torres C, Vella S, de la Eva R. Follow-up on metabolic markers in children treated for obstructive sleep apnea. Am J Respir Crit Care Med. 2006;174(4):455-60.

9. Alberti KGM, Zimmet P, Shaw J. The metabolic syndrome-a new worldwide definition. Lancet. 2005;366(9491):1059-62.

10. Organization WH: Definition, diagnosis and classification of diabetes mellitus and its complications: report of a WHO consultation. Part 1, Diagnosis and classification of diabetes mellitus. World Health Organization; 1999.

11. Boney CM, Verma A, Tucker R, Vohr BR. Metabolic syndrome in childhood: association with birth weight, maternal obesity, and gestational diabetes mellitus. Pediatrics. 2005;115(3):e290-6.

12. de Ferranti SD, Gauvreau K, Ludwig DS, Neufeld EJ, Newburger JW, Rifai N. Prevalence of the metabolic syndrome in American adolescents: findings from the Third National Health and Nutrition Examination Survey. Circulation. 2004;110(16):2494-7.

13. Cook S, Weitzman M, Auinger P, Nguyen M, Dietz WH. Prevalence of a metabolic syndrome phenotype in adolescents: findings from the third National Health and Nutrition Examination Survey, 1988-1994. Arch Pediatr Adolesc Med. 2003;157(8):821-7.

14. Al-Hamad D, Raman V. Metabolic syndrome in children and adolescents. Transl Pediatrics. 2017;6(4):397-407.
15. Friend A, Craig L, Turner S. The prevalence of metabolic syndrome in children: a systematic review of the literature. Metab Syndr Related Disord. 2013;11(2):71-80.

16. Agudelo GM, Bedoya G, Estrada A, Patiño FA, Muñoz AM, Velásquez CM. Variations in the prevalence of metabolic syndrome in adolescents according to different criteria used for diagnosis: which definition should be chosen for this age group? Metab Syndr Related Disord. 2014;12(4):202-9.

17. Poyrazoglu S, Bas F, Darendeliler F. Metabolic syndrome in young people. Curr Opin Endocrinol Diabetes Obes. 2014;21(1):56-63.

18. Kelishadi R, Hovsepian S, Djalalinia S, Jamshidi F, Qorbani M. A systematic review on the prevalence of metabolic syndrome in Iranian children and adolescents. J Res Med Sci. 2016;21:90.

19. Wang LX, Gurka MJ, Deboer MD. Metabolic syndrome severity and lifestyle factors among adolescents. Minerva Pediatr. 2018;70(5):467-75.

20. Gepstein V, Weiss R. Obesity as the main risk factor for metabolic syndrome in children. Front Endocrinol. 2019;10:568.

21. Taskinen M-R, Packard CJ, Borén J. Dietary fructose and the metabolic syndrome. Nutrients. 2019;11(9):1987.

22. Mortera RR, Bains Y, Gugliucci A. Fructose at the crossroads of the metabolic syndrome and obesity epidemics. Front Biosci (Landmark edition). 2019;24:186-211.

23. Weihe P, Weihrauch-Blüher S. Metabolic syndrome in children and adolescents: diagnostic criteria, therapeutic options and perspectives. Curr Obes Rep. 2019;8(4):472-9.

24. Swinburn BA, Kraak VI, Allender S, Atkins VJ, Baker PI, Bogard JR, Brinsden $\mathrm{H}$, Calvillo A, De Schutter O, Devarajan R, et al. The global syndemic of obesity, undernutrition, and climate change: the lancet commission report. Lancet (London, England). 2019;393(10173):791-846.

25. Choukem SP, Tochie JN, Sibetcheu AT, Nansseu JR, Hamilton-Shield JP. Overweight/obesity and associated cardiovascular risk factors in sub-Saharan African children and adolescents: a scoping review. Int J Pediatric Endocrinol. 2020;2020:6.

26. Labadarios D. Malnutrition in the developing world: the triple burden South Afr J Clin Nutr. 2005;18(2):119-21.

27. Moher D, Liberati A, Tetzlaff J, Altman DG. Preferred reporting items for systematic reviews and meta-analyses: the PRISMA statement. Ann Intern Med. 2009;151(4):264-9.

28. Munn Z, Moola S, Lisy K, Riitano D, Tufanaru C. Methodological guidance for systematic reviews of observational epidemiological studies reporting prevalence and cumulative incidence data. Int J Evid Based Healthcare. 2015;13(3):147-53.

29. World Bank, Country list based on GNI per capita in 2019. https://datah elpdesk.worldbank.org/knowledgebase/articles/906519-world-bankcountry-and-lending-groups. Accessed July 2020.

30. Sterne JA, Egger M. Funnel plots for detecting bias in meta-analysis: guidelines on choice of axis. J Clin Epidemiol. 2001;54(10):1046-55.

31. Rücker G, Schwarzer G, Carpenter JR, Schumacher M. Undue reliance on 12 in assessing heterogeneity may mislead. BMC Med Res Methodol. 2008;8(1):79.

32. Higgins JP, Thompson SG. Quantifying heterogeneity in a meta-analysis. Stat Med. 2002;21(11):1539-58.

33. Zhu Y, Zheng H, Zou Z, Jing J, Ma Y, Wang H, Luo J, Zhang X, Luo C, Wang $\mathrm{H}$, et al. Metabolic syndrome and related factors in chinese children and adolescents: analysis from a chinese national study. J Atheroscler Thromb. 2020;27(6):534-44.

34. Mahajan N, Kshatriya GK. Prevalence of metabolic syndrome and associated risk factors among tribal adolescents of Gujarat. Diabetes Metab Syndr Clin Res Rev 2020;14(5):995-9.

35. Dejavitte RA, Enes CC, Nucci LB. Prevalence of metabolic syndrome and its associated factors in overweight and obese adolescents. J Pediatr Endocrinol Metab. 2020:33(2):233-9.

36. Bekel GE, Thupayagale-Tshweneagae G. Prevalence and associated factors of metabolic syndrome and its individual components among adolescents. Int J Public Health Sci. 2020;9(1):46-56.

37. Ahmadi N, Seyed Mahmood S, Mohammadi MR, Mirzaei M, Mehrparvar AH, Ardekani SMY, Sarebanhassanabadi M, Nilforoshan N, Mostafavi S-A. Prevalence of abdominal obesity and metabolic syndrome in children and adolescents: a community based cross-sectional study. Iranian J Public Health. 2020;49(2):360. 
38. Zhao Y, Yu Y, Li H, Li M, Zhang D, Guo D, Yu X, Lu C, Wang H. The association between metabolic syndrome and biochemical markers in Beijing adolescents. Int J Environ Res Public Health. 2019;16(22):4557.

39. Zhang Y, Hu J, Li Z, Li T, Chen M, Wu L, Liu W, Han H, Yao R, Fu L. A novel indicator of lipid accumulation product associated with metabolic syndrome in Chinese children and adolescents. Diabetes Metab Syndr Obes Targets Therapy. 2019;12:2075.

40. Wang J, Perona JS, Schmidt-RioValle J, Chen Y, Jing J, González-Jiménez E. Metabolic syndrome and its associated early-life factors among chinese and spanish adolescents: a pilot study. Nutrients. 2019;11(7):1568.

41. Oliveira RG, Guedes DP. Determinants of lifestyle associated with metabolic syndrome in Brazilian adolescents. Nutr Hosp. 2019;36(4):826-33.

42. Suebsamran P, Pimpak T, Thani P, Chamnan P. The Metabolic syndrome and health behaviors in school children aged 13-16 years in ubon Ratchathani: UMeSIA Project. Metab Syndr Related Disord. 2018;16(8):425-32.

43. Gupta A, Sachdeva A, Mahajan N, Gupta A, Sareen N, Pandey RM, Ramakrishnan L, Sati HC, Sharma B, Sharma N, et al. Prevalence of pediatric metabolic syndrome and associated risk factors among school-age children of 10-16 years living in district Shimla, Himachal Pradesh India. Indian J Endocrinol Metab. 2018;22(3):373-8.

44. Dos Santos MC, de Castro Coutinho APC, de Souza DM, Yabunaka LAM, Guedes DP, Oesterreich SA. Correlates of metabolic syndrome among young Brazilian adolescents population. Nutr J. 2018;17(1):66.

45. Andaki ACR, Mendes EL, Brito CJ, Amorim PRdS, Wood R, Tinoco ALA: Prevalence and factors associated with metabolic syndrome in 6-10-year-old children. Motriz: Revista de Educação Física. 2018; 24(3).

46. Sekokotla MA, Goswami N, Sewani-Rusike CR, Iputo JE, Nkeh-Chungag BN. Prevalence of metabolic syndrome in adolescents living in Mthatha, South Africa. Ther Clin Risk Manag. 2017;13:131.

47. Cornejo-Monthedoro A, Negreiros-Sanchez I, Del Aguila C, Ysla-Marquillo M, Mayta-Tristan P. Association between dietary glycemic load and metabolic syndrome in obese children and adolescents. Archivos Argentinos de Pediatria. 2017;115(4):323-30.

48. Wang J, Zhu Y, Cai L, Jing J, Chen Y, Mai J, Ma L, Ma Y, Ma J. Metabolic syndrome and its associated early-life factors in children and adolescents: a cross-sectional study in Guangzhou, China. Public Health Nutrition. 2016:19(7):1147-54.

49. Suarez-Ortegón MF, Aguilar-de Plata C. Prevalence of metabolic syndrome in children aged 5-9 years from southwest Colombia: a cross-sectional study. World J Pediatrics WJP. 2016;12(4):477-83.

50. Rinaldi AEM, Gabriel GFCP, Moreto F, Corrente JE, McLellan KCP, Burini RC. Dietary factors associated with metabolic syndrome and its components in overweight and obese Brazilian schoolchildren: a crosssectional study. Diabetol Metab Syndr. 2016;8(1):58.

51. Ramírez-Vélez R, Anzola A, Martinez-Torres J, Vivas A, Tordecilla-Sanders A, Prieto-Benavides D, Izquierdo M, Correa-Bautista JE, Garcia-Hermoso A. Metabolic syndrome and associated factors in a population-based sample of schoolchildren in Colombia: the FUPRECOL study. Metab Syndr Related Disord. 2016;14(9):455-62.

52. Kuschnir MCC, Bloch KV, Szklo M, Klein CH, Barufaldi LA. Abreu GdA Schaan B, Veiga GVd, Silva TLNd, De Vasconcellos MT: ERICA: prevalence of metabolic syndrome in Brazilian adolescents. Rev Saude Publica. 2016;50:11.

53. Karandish M, Hosseinpour M, Rashidi H, Latifi SM, Moravej Aleali A Comparison of components of metabolic syndrome among metabolically obese Normal weight, metabolically benign Normal weight, and metabolically abnormal obese Iranian children and adolescents in Ahvaz. J Nutr Food Security. 2016;1(1):9-15.

54. de Carvalho RBN, de Sousa Nobre R, Guimarães MR, Teixeira SEXM da Silva ARV. Risk factors associated with the development of metabolic syndrome in children and adolescents. Acta Paul Enferm. 2016;29(4):439-45.

55. Vukovic R, Zdravkovic D, Mitrovic K, Milenkovic T, Todorovic S, Vukovic A Soldatovic I. Metabolic syndrome in obese children and adolescents in Serbia: prevalence and risk factors. J Pediatric Endocrinol Metab JPEM. 2015;28(7-8):903-9.

56. Rosini N, Moura SA, Rosini RD, Machado MJ, Silva EL. Metabolic Syndrome and Importance of Associated Variables in Children and Adolescents in Guabiruba - SC Brazil. Arquivos brasileiros de cardiologia. 2015:105(1):37-44.
57. Medinaa ON, Arriagaa RV, Valverdeb LF, Lópeza CPR, Skidmorec OM, Torresd MCG, Camachoa MEI, Lópeza SG: Prevalence of metabolic syndrome in overweight and obese schoolchildren. 2015.

58. Damak J, Abid M. Prevalence of metabolic syndrome and its components among overweight and obese secondary school adolescent in Sfax Tunisia. Int J. 2015;3(1):1-6.

59. Bortoloti DS, Pizzi J, Pavão FH, Velasquez PAG, Costa LD, Fernandes RA Cyrino ES. Prevalence of metabolic syndrome and associated factors in 11-to 17-year-old adolescents. Revista Brasileira de Cineantropometria \& Desempenho Humano. 2015;17(6):683-92.

60. Bhat RA, Paray I, Zargar S, Ganie A, Khan I. Prevalence of the metabolic syndrome among North Indian adolescents using Adult Treatment Panel III and pediatric International Diabetic Federation definitions. Arch Med Health Sci. 2015;3(1):44.

61. Bhalavi V, Deshmukh PR, Goswami K, Garg N. Prevalence and correlates of metabolic syndrome in the adolescents of rural Wardha. Indian J Commun Med. 2015;40(1):43.

62. Villalobos Reyes M, Mederico M, Paoli de Valeri M, Briceño Y, Zerpa Y, Gómez-Pérez R, Camacho N, Martínez JL, Valeri L, Arata-Bellabarba G. Metabolic syndrome in children and adolescents from Mérida city, Venezuela: Comparison of results using local and international reference values (CREDEFAR study). Endocrinologia y nutricion : organo de la Sociedad Espanola de Endocrinologia y Nutricion. 2014;61(9):474-85.

63. Tavares Giannini D, Caetano Kuschnir MC, Szklo M. Metabolic syndrome in overweight and obese adolescents: a comparison of two different diagnostic criteria. Ann Nutr Metab. 2014;64(1):71-9.

64. Rerksuppaphol L, Rerksuppaphol S. Prevalence of metabolic syndrome in Thai children: a cross-sectional study. J Clin Diagnostic Res JCDR. 2014;8(4):PC04.

65. Rashidi H, Payami SP, Latifi SM, Karandish M, Moravej Aleali A, Aminzadeh M, Riahi K, Ghasemi M. Prevalence of metabolic syndrome and its correlated factors among children and adolescents of Ahvaz aged 10-19. J Diabetes Metab Disord. 2014;13(1):53.

66. Pitangueira JCD, Silva LR, de Santana MLP, da Silva MdCM, de Farias Costa PR, D'Almeida V, de Oliveira Assis AM. Metabolic syndrome and associated factors in children and adolescents of a Brazilian municipality. Nutr Hosp. 2014;29(4):865-72.

67. Mbowe O, Diaz A, Wallace J, Mazariegos M, Jolly P. Prevalence of metabolic syndrome and associated cardiovascular risk factors in Guatemalan school children. Matern Child Health J. 2014;18(7):1619-27.

68. Li P, Jiang R, Li L, Liu C, Yang F, Qiu Y. Prevalence and risk factors of metabolic syndrome in school adolescents of northeast China. J Pediatric Endocrinol Metab JPEM. 2014;27(5-6):525-32.

69. Gobato AO, Vasques AC, Zambon MP. Barros Filho Ade A, Hessel G: Metabolic syndrome and insulin resistance in obese adolescents. Revista paulista de pediatria : orgao oficial da Sociedade de Pediatria de Sao Paulo. 2014:32(1):55-62.

70. Fadzlina A, Harun F, Haniza MN, Al Sadat N, Murray L, Cantwell MM, Su TT, Majid HA, Jalaludin MY. Metabolic syndrome among 13 year old adolescents: prevalence and risk factors. BMC public health 2014. Springer; 2014. pp. S7.

71. Casavalle PL, Lifshitz F, Romano LS, Pandolfo M, Caamaño A, Boyer PM, Rodríguez PN, Friedman SM. Prevalence of dyslipidemia and metabolic syndrome risk factor in overweight and obese children. Pediatric Endocrinol Rev PER. 2014;12(2):213-23.

72. Yee KT, Thwin T, Khin EE, Zaw KK, Oo NN, Oo AM, Maw LZ, Kyaw MT, Aung NN. Metabolic syndrome in obese and normal weight myanmar children. J ASEAN Federation Endocrine Soc. 2013:28(1):52-5.

73. Wang Q, Yin J, Xu L, Cheng H, Zhao X, Xiang H, Lam HS, Mi J, Li M. Prevalence of metabolic syndrome in a cohort of Chinese schoolchildren: comparison of two definitions and assessment of adipokines as components by factor analysis. BMC Public Health. 2013;13:249.

74. Tandon N, Garg MK, Singh Y, Marwaha RK. Prevalence of metabolic syndrome among urban Indian adolescents and its relation with insulin resistance (HOMA-IR). J Pediatric Endocrinol Metab. 2013:26(11-12):1123-30.

75. Suárez-Ortegón MF, Ramírez-Vélez R, Mosquera M, Méndez F, Aguilarde Plata C. Prevalence of metabolic syndrome in urban Colombian adolescents aged 10-16 years using three different pediatric definitions. J Trop Pediatr. 2013;59(2):145-9. 
76. Singh N, Parihar RK, Saini G, Mohan SK, Sharma N, Razaq M. Prevalence of metabolic syndrome in adolescents aged 10-18 years in Jammu, J and K. Indian J Endocrinol Metab. 2013;17(1):133.

77. Sewaybricker LE, Antonio M, Mendes RT, Ade BFA, Zambon MP. Metabolic syndrome in obese adolescents: what is enough? Revista da Associacao Medica Brasileira (1992). 2013;59(1):64-71.

78. Sarrafzadegan N, Gharipour M, Sadeghi M, Nouri F, Asgary S, Zarfeshani S. Differences in the prevalence of metabolic syndrome in boys and girls based on various definitions. ARYA Atheroscler. 2013;9(1):70-6.

79. Rizzo AC, Goldberg TB, Silva CC, Kurokawa CS, Nunes HR, Corrente JE. Metabolic syndrome risk factors in overweight, obese, and extremely obese Brazilian adolescents. Nutr J. 2013;12:19.

80. Qorbani M, Kelishadi R, Farrokhi-Khajeh-Pasha Y, Motlagh M, Aminaee T, Ardalan G, Asayesh H, Shafiee G, Taslimi M, Poursafa P, et al. Association of anthropometric measures with cardiovascular risk factors and metabolic syndrome in normal-weight children and adolescents: the CASPIAN III study. Obes Facts. 2013;6(5):483-92.

81. Khashayar P, Heshmat R, Qorbani M, Motlagh ME, Aminaee T, Ardalan G, Farrokhi-Khajeh-Pasha Y, Taslimi M, Larijani B, Kelishadi R. Metabolic syndrome and cardiovascular risk factors in a national sample of adolescent population in the Middle East and North Africa: the CASPIAN III Study. Int J Endocrinol. 2013;2013:702095.

82. Andrabi SM, Bhat MH, Andrabi SR, Kamili MM, Imran A, Nisar I, Nisar U. Prevalence of metabolic syndrome in 8-18-year-old school-going children of Srinagar city of Kashmir India. Indian J Endocrinol Metab. 2013;17(1):95.

83. Xu H, Li Y, Liu A, Zhang Q, Hu X, Fang H, Li T, Guo H, Li Y, Xu G. Prevalence of the metabolic syndrome among children from six cities of China. BMC Public Health. 2012;12(1):13.

84. Saffari F, Jalilolghadr S, Esmailzadehha N, Azinfar P. Metabolic syndrome in a sample of the 6-to 16-year-old overweight or obese pediatric population: a comparison of two definitions. Ther Clin Risk Manag. 2012;8:55.

85. Nasreddine L, Naja F, Tabet M, Habbal M-Z, El-Aily A, Haikal C, Sidani S, Adra $\mathrm{N}$, Hwalla N. Obesity is associated with insulin resistance and components of the metabolic syndrome in Lebanese adolescents. Ann Hum Biol. 2012;39(2):122-8.

86. Mehrkash M, Kelishadi R, Mohammadian S, Mousavinasab F, Qorbani M, Hashemi ME, Asayesh H, Poursafa P, Shafa N. Obesity and metabolic syndrome among a representative sample of Iranian adolescents. Southeast Asian J Trop Med Public Health. 2012;43(3):756-63.

87. Jamoussi H, Mahjoub F, Sallemi H, Berriche O, Ounaissa K, Amrouche C, Blouza S. Metabolic syndrome in Tunisian obese children and adolescents. Tunis Med. 2012;90(1):36-40

88. Cua SC. Prevalence of metabolic syndrome in overweight and obese filipino adolescents based on the IDF definition. J ASEAN Federation Endocrine Soc. 2012;27(1):82-82

89. Costa RF, Santos NS, Goldraich NP, Barski TF, Andrade KS, Kruel LF. Metabolic syndrome in obese adolescents: a comparison of three different diagnostic criteria. Jornal de Pediatria. 2012;88(4):303-9.

90. Chen F, Wang Y, Shan X, Cheng H, Hou D, Zhao X, Wang T, Zhao D, Mi J. Association between childhood obesity and metabolic syndrome: evidence from a large sample of Chinese children and adolescents. PLOS ONE. 2012;7(10):e47380.

91. Hassan NE, El-Masry SA, Fouad WA, Sherif L, Elwakkad A, Anwar M, Zaki ST. Prevalence of metabolic syndrome among obese school students. e-SPEN. 2011;6(6):e248-52.

92. Panamonta O, Thamsiri N, Panamonta M. Prevalence of type II diabetes and metabolic syndrome among overweight school children in Khon Kaen, Thailand. J Med Assoc Thailand = Chotmaihet Thangphaet. 2010;93(1):56-60.

93. LiuW, Lin R, Liu A, Du L, Chen Q. Prevalence and association between obesity and metabolic syndrome among Chinese elementary school children: a school-based survey. BMC Public Health. 2010;10(1):780.

94. Khader Y, Batieha A, Jaddou H, El-Khateeb M, Ajlouni K. Metabolic syndrome and its individual components among Jordanian children and adolescents. Int J Pediatric Endocrinol. 2010;2010(1):316170.

95. Juárez-López C, Klünder-Klünder M, Medina-Bravo P, Madrigal-Azcárate A, Mass-Díaz E, Flores-Huerta S. Insulin resistance and its association with the components of the metabolic syndrome among obese children and adolescents. BMC Public Health. 2010;10(1):318.

96. Hirschler V, Oestreicher K, Maccallini G, Aranda C. Relationship between obesity and metabolic syndrome among Argentinean elementary school children. Clin Biochem. 2010;43(4-5):435-41.
97. Ella NAA, Shehab DI, Ismail MA, Maksoud AA. Prevalence of metabolic syndrome and insulin resistance among Egyptian adolescents 10 to 18 years of age. J Clin Lipidol. 2010;4(3):185-95.

98. Afkhami-Ardekani M, Zahedi-Asl S, Rashidi M, Atifah M, Hosseinpanah F, Azizi F. Incidence and trend of a metabolic syndrome phenotype among Tehranian adolescents: findings from the Tehran Lipid and Glucose Study, 1998-2001 to 2003-2006. Diabetes Care. 2010;33(9):2110-2.

99. Seki M, Matsuo T, Carrilho AJ. Prevalence of metabolic syndrome and associated risk factors in Brazilian schoolchildren. Public Health Nutr. 2009;12(7):947-52.

100. Salem Z, Vazirinejad R. Prevalence of obesity and metabolic syndrome in adolescent girls in South East of Iran. Pak J Med Sci. 2009;25(2):196-200.

101. Mirhosseini N-Z, Mohd Yusoff NA, Shahar S, Parizadeh SMR, Ghayour Mobarhen M, Shakery MT. Prevalence of the metabolic syndrome and its influencing factors among adolescent girls in Mashhad Iran. Asia Pac J Clin Nutr. 2009;18(1):131

102. Matsha T, Hassan S, Bhata A, Yako Y, Fanampe B, Somers A, Hoffmann M, Mohammed Z, Erasmus RT. Metabolic syndrome in 10-16-year-old learners from the Western Cape, South Africa: comparison of the NCEP ATP III and IDF criteria. Atherosclerosis. 2009;205(2):363-6.

103. Li Y, Yang X, Zhai F, Kok FJ, Zhao W, Piao J, Zhang J, Cui Z, Ma G. Prevalence of the metabolic syndrome in Chinese adolescents. Br J Nutr. 2008;99(3):565-70.

104. Caceres M,Teran CG, RodriguezS, Medina M. Prevalence of insulin resistance and its association with metabolic syndrome criteria among Bolivian children and adolescents with obesity. BMC Pediatrics. 2008;8:31.

105. Singh R, Bhansali A, Sialy R, Aggarwal A. Prevalence of metabolic syndrome in adolescents from a north Indian population. Diabetic Med. 2007;24(2):195-9.

106. Kelishadi R, Ardalan G, Gheiratmand R, Adeli K, Delavari A, Majdzadeh R. Paediatric metabolic syndrome and associated anthropometric indices: the CASPIAN Study. Acta paediatrica. 2006;95(12):1625-34.

107. Esmaillzadeh A, Mirmiran P, Azadbakht L, Etemadi A, Azizi F. High prevalence of the metabolic syndrome in Iranian adolescents. Obesity (Silver Spring, Md). 2006;14(3):377-82.

108. Rodríguez-Morán M, Salazar-Vázquez B, Violante R, Guerrero-Romero F. Metabolic syndrome among children and adolescents aged $10-18$ years. Diabetes Care. 2004;27(10):2516-7.

109. Tailor AM, Peeters PH, Norat T, Vineis P, Romaguera D. An update on the prevalence of the metabolic syndrome in children and adolescents. Int J Pediatric Obesity. 2010;5(3):202-13.

110. Ye P, Yan Y, Ding W, Dong H, Liu Q, Huang G, Mi J: Prevalence of metabolic syndrome in Chinese children and adolescents: a meta-analysis. 2015.

111. Graf C, Ferrari N. Metabolic syndrome in children and adolescents. Visceral Med. 2016;32(5):357-62

112. Titmuss AT, Srinivasan S. Metabolic syndrome in children and adolescents: old concepts in a young population. J Paediatr Child Health. 2016;52(10):928-34.

113. Wang VH, Min J, Xue H, Du S, Xu F, Wang H, Wang Y. What factors may contribute to sex differences in childhood obesity prevalence in China? Public Health Nutr. 2018;21(11):2056-64.

114. Akbarzadeh Z, Nourian M, Hovsepian S, Kelishadi R. Dietary patterns and metabolic syndrome in children and adolescents: a systematic review. J Pediatrics Rev. 2018;6(2):2-13.

115. Tian Y, Su L, Wang J, Duan X, Jiang X. Fruit and vegetable consumption and risk of the metabolic syndrome: a meta-analysis. Public Health Nutr. 2018;21(4):756-65.

116. Aurino E, Fernandes M, Penny ME. The nutrition transition and adolescents' diets in low-and middle-income countries: a cross-cohort comparison. Public Health Nutrition. 2017;20(1):72-81.

117. Ford ND, Patel SA, Narayan KV.Obesity in low-and middle-income countries: burden, drivers, and emerging challenges. Annu Rev Public Health. 2017;38:145-64

118. Popkin BM, Adair LS, Ng SW. Global nutrition transition and the pandemic of obesity in developing countries. Nutr Rev. 2012;70(1):3-21.

\section{Publisher's Note}

Springer Nature remains neutral with regard to jurisdictional claims in published maps and institutional affiliations. 